\title{
Growth patterns of craniopharyngiomas: clinical analysis of 226 patients
}

\author{
*Jun Pan, MD, PhD, ${ }^{2}$ Songtao Qi, MD, PhD, ${ }^{1}$ Yi Liu, MD, ${ }^{1}$ Yuntao Lu, MD,1 Junxiang Peng, MD, \\ XiAn Zhang, MD, ${ }^{1}$ YiKai Xu, MD, ${ }^{3}$ Guang-long Huang, MD, ${ }^{1}$ and Jun Fan, MD ${ }^{1}$
}

Departments of ${ }^{1}$ Neurosurgery, ${ }^{2}$ Pediatric Neurosurgery, and ${ }^{3}$ Medical Imaging, Nanfang Hospital, Southern Medical University, Guangzhou, People's Republic of China

\begin{abstract}
OBJECTIVE Craniopharyngiomas (CPS) are rare epithelial tumors that are often associated with an enigmatic and unpredictable growth pattern. Understanding the growth patterns of these tumors has a direct impact on surgical planning and may enhance the safety of radical tumor removal. The aim of this study was to analyze the growth patterns and surgical treatment of CPs with a focus on the involvement of the hypothalamopituitary axis and the relationship of the tumor to the arachnoid membrane and surrounding structures.
\end{abstract}

METHODS Clinical data from 226 consecutive patients with primary CP were retrospectively reviewed. Tumor location and the relationship of the tumor to the third ventricle floor and the pituitary stalk were evaluated using preoperative MRI and intraoperative findings. A topographic classification scheme was proposed based on the site of tumor origin and tumor development. The clinical relevance of this classification on patient presentation and outcomes was also analyzed.

RESULTS The growth of CPS can be broadly divided into 3 groups based on the site of tumor origin and on tumormeningeal relationships: Group I, infrasellar/infradiaphragmatic CPs (Id-CPs), which mainly occurred in children; Group II, suprasellar subarachnoid extraventricular CPs (Sa-CPs), which were mainly observed in adults and rarely occurred in children; and Group III, suprasellar subpial ventricular CPs (Sp-CPs), which commonly occurred in both adults and children. Tumors in each group may develop complex growth patterns during vertical expansion along the pituitary stalk. Tumor growth patterns were closely related to both clinical presentation and outcomes. Patients with Sp-CPs had more prevalent weight gain than patients with Id-CPs or Sa-CPs; the rates of significant weight gain were $41.7 \%$ for children and $16.7 \%$ for adults with Sp-CPs, $2.2 \%$ and $7.1 \%$ for those with Id-CPs, and $12.5 \%$ and $2.6 \%$ for those with Sa-CPs (p $<0.001$ ). Moreover, patients with Sp-CPs had increased hypothalamic dysfunction after radical removal; $39 \%$ of patients with $\mathrm{Sp}-\mathrm{CPs}, 14.5 \%$ with Id-CPs, and $17.4 \%$ with Sa-CPs had high-grade hypothalamic dysfunction in the first 2 postoperative years $(p<0.001)$.

CONCLUSIONS The classification of CPs based on growth pattern may elucidate the best course of treatment for this formidable tumor. More tailored, individualized surgical strategies based on tumor growth patterns are mandatory to provide long-term tumor control and to minimize damage to hypothalamic structures. Differences in the distribution of growth patterns between children and adults imply that hierarchical comparison is necessary when investigating outcomes and survival across treatment paradigms in patients with $\mathrm{CP}$.

http://thejns.org/doi/abs/10.3171/2015.7.PEDS14449

KEY WORDS classification; craniopharyngiomas; growth pattern; pituitary stalk; oncology

$\mathrm{C}$ RANIOPHARYNGIOMAS (CPs) are formidable and complex benign tumors of the sellar and suprasellar regions. Although the optimal treatment for CP remains controversial, there is consensus that surgical treatment should be tailored according to tumor localization..$^{53}$ Selecting an optimal surgical approach based on the tumor growth pattern is mandatory to achieve complete resection with minimal compromise to surrounding vital neurovascular structures. For this reason, many topographic classifications have been proposed based on tumor location and extension, with relationships of the tumor to the sellar diaphragm, optic chiasm, pituitary stalk, and third

ABBREVIATIONS ACP = adamantinomatous craniopharyngioma; $\mathrm{ASPS}=$ arachnoidal sleeve around the pituitary stalk; $\mathrm{BMI}=$ body mass index; $\mathrm{CP}=\mathrm{craniopharyngioma;}$ HSS = hypothalamic status score; OS = overall survival; $\mathrm{PCP}=$ papillary craniopharyngioma; PFS = progression-free survival; TSH = thyroid-stimulating hormone; TVF = third ventricle floor.

SUBMITTED August 22, 2014. ACCEPTED July 13, 2015.

INCLUDE WHEN CITING Published online December 4, 2015; DOI: 10.3171/2015.7.PEDS14449.

* Drs. Pan and Qi contributed equally to this work. 
ventricle floor (TVF) being the main determinants taken into consideration. $6,27,32,33,54,55,58,62,63$ These classification schemes are useful in understanding tumor topography and provide clues to aid in the selection of the optimal surgical approach for tumor removal. However, a classification system capable of describing both the details of the tumor origin and hypothalamic involvement patterns has yet to be reported in the literature..$^{46}$

In our preliminary study, we reported the surgical relevance of the anatomical relationship of the tumor to arachnoidea around the pituitary stalk, and we proposed a new morphological classification that divided CP growth into 4 basic patterns. ${ }^{49}$ Growth pattern variants with distinct morphological features were also observed. ${ }^{49}$ Additionally, the study concentrated on the relationship of CPs to surrounding membranous structures, which are always included in the surgical plane during tumor resection. Although the classification was useful in understanding the diverse growth patterns of CPs, it was complex and theoretical to a certain extent. In the current study, we have attempted to simplify the classification and enhance its clinical practicality.

\section{Methods \\ Review of Clinical Data \\ Patient Details}

Patients in this study were recruited from among all patients with CP who were admitted to the Nanfang Hospital of the Southern Medical University between January 1996 and December 2011. A total of 311 consecutive patients underwent surgical removal of $\mathrm{CP}$ at the hospital during this period. Eighty-five patients with recurrent tumors were excluded. All pathological materials and medical records of the remaining 226 patients with primary tumors were reviewed, and the $\mathrm{CP}$ diagnosis was histologically confirmed. Of the 226 patients with CP, 96 patients suffered from childhood-onset tumors (age $\leq 16$ years at the time of diagnosis; 58 boys and 38 girls), and 130 patients suffered from adult-onset tumors (87 men and 43 women). The average age at the time of surgery was $9.0 \pm 4.6$ years for childhood patients (range 1-27 years) and $39.8 \pm 13.3$ years for adult patients (range 17-72 years).

\section{Clinical Data Assessment}

Data points for clinical presentation, preoperative endocrine status, imaging findings, operative details, pathology reports, and clinical outcomes were reviewed. Pituitary function was evaluated by laboratory assessment of adrenocorticotropic hormone, growth hormone, insulin-like growth factor, prolactin, thyroid-stimulating hormone (TSH), thyroxin, follicle-stimulating hormone, luteinizing hormone, testosterone, and morning cortisol levels. A provocation test was applied as needed. Adrenocorticotropic hormone deficiency was defined as a peak cortisol value of less than $500 \mathrm{nmol} / \mathrm{L}$ after provocative testing (via an insulin hypoglycemia, glucagon, or short synacthen test) or a baseline plasma cortisol level of less than $100 \mathrm{nmol} / \mathrm{l}$. Growth hormone deficiency was defined as a peak value of less than $7 \mathrm{ng} / \mathrm{ml}$ after effective stimulation in an insulin stimulation test or if patients exhib- ited delayed growth and development and a short stature (height $>3$ SDs below the mean for a particular age and sex). TSH deficiency was diagnosed on the basis of low or "inappropriately normal" TSH with free thyroxine levels below the normal reference values. The development of secondary sex characteristics was evaluated in adolescent patients (girls aged $>12$ years, boys aged $>15$ years). A diagnosis of diabetes insipidus was comprehensively determined according to urine volume ( $>3 \mathrm{~L} / 24 \mathrm{hrs}$ ) and urine osmolality $(<300 \mathrm{mOsm} / \mathrm{kg})$.

Preoperative CT and MRI scans for each patient were reviewed and scored by the same radiologist (Y.X.), who was blinded to the clinical data. Tumor size was calculated as the maximum measurable dimension on MRI. The presence of hydrocephalus was classified as follows: no, without ventricular widening, or yes, CT- and/or MRIconfirmed ventricular widening with an Evans' index $\geq$ 0.30 .

\section{Surgery and Classification of Tumors}

All 226 patients in this series underwent resection with the aim of total tumor removal. The procedures were performed under the operating room microscope mainly by 2 surgeons (S.Q. and J.P.) and were video recorded. To verify tumor location and its topographic relationships to the sellar diaphragm, pituitary stalk, arachnoid membranes around the stalk, and TVF, we retrospectively reviewed and analyzed the preoperative MR images and intrasurgical findings for each patient (J.P. and Y.L.). A topographic classification of the tumors was proposed based on a combination of tumor location and the relationship of the tumor to the membranous structure, stalk, and TVF. The extent of tumor removal was determined by intrasurgical findings and postoperative contrast-enhanced MRI. Total tumor removal was declared when operative impression and postoperative MRI documented no residual tumor.

\section{Follow-Up}

Follow-up was scheduled at 3 and 9 months after surgery and annually thereafter. Tumor recurrence was determined according to follow-up imaging, which was performed at regular intervals based on the clinical pictures and the physician's preference, with or without associated signs and symptoms of recurrence. Each patient's height and weight were recorded at all follow-up visits. The maximum weight gain in the first 2 postoperative years was used for analysis. Body mass index (BMI) was calculated with the following formula: (weight in $\mathrm{kg}$ )/(height in meters $)^{2}$. Postoperative weight categories for adult patients were classified as normal (BMI < 25), overweight (BMI $25-30)$, or obesity (BMI > 30). Weight in children was evaluated by comparing BMI with the reference values of Chinese children, and weight categories were classified as normal, obesity (BMI greater than $+2 \mathrm{SD}$ ), and extreme obesity (BMI greater than +4 SDs). Other hypothalamic disturbances, such as hyperphagia, memory deficits, thermoregulatory abnormalities, emotionally labile behavior, and sleep-wake cycle disruption, were also evaluated and recorded based on information from the patients and their families as well as records of the follow-up office visits. The ultimate hypothalamic status score (HSS) in children 
was evaluated using the 4-tiered grading scale created by De Vile et al. ${ }^{16}$ For facilitating statistical analysis, the postoperative hypothalamic status in adult patients was evaluated using a 4-tiered grading scale as follows: Grade 1, normal hypothalamic function; Grade 2, overweight (25 $<$ BMI $\leq 30)$ and lack of behavior indicative of hypothalamic dysfunction; Grade 3, obesity (BMI > 30) or weight gain without hyperphagia or an associated change in affective behavior or memory; and Grade 4, obesity (BMI $>30$ ) and hyperphagia with cognitive dysfunction, rage behavior, and impaired thirst or disturbances of thermoregulation concomitant with sleep-wake disruption or extreme emaciation.

\section{Statistical Analysis}

Differences in tumor growth patterns between age groups and differences in imaging features among the growth pattern groups were analyzed using the chi-square test or Fisher's exact test. Differences in tumor size between groups were analyzed using the Student t-test. The Wilcoxon rank-sum test (Mann-Whitney U-test) was used to compare nonparametric variables between groups. The overall survival (OS) and progression-free survival (PFS) curves were generated using the Kaplan-Meier method, and differences in survival and recurrence rates in each group were evaluated using the log-rank test. SPSS 17.0 statistical software was used for all analyses. A p value $<$ 0.05 was considered statistically significant.

\section{Results}

\section{Classification of CPs}

Theoretically, CPs initially develop along the pituitary stalk in 5 basic growth patterns based on their anatomical location and relationship to the arachnoidal sleeve around the pituitary stalk (ASPS) (Fig. 1). ${ }^{56}$ Tumor anatomical location and development combined with tumor site of origin allowed for precise CP classification. CPs were classified into 3 groups: Group I, infradiaphragmatic CPs (Id-CPs); Group II, suprasellar subarachnoid extraventricular CPs (Sa-CPs); and Group III, suprasellar subpial ventricular CPs (Sp-CPs) (Table 1). Each tumor group can develop complex subsets along the hypothalamopituitary axis during tumor development. These growth pattern variants could be interpreted by the aforementioned 5 basic growth patterns. A detailed description of the $3 \mathrm{CP}$ groups is presented below.

\section{Group I: Id-CPs}

The Id-CPs usually demonstrated marked enlargement of the pituitary fossa and a large rounded and symmetrical extension to the suprasellar space (Fig. 2a). Tumor growth
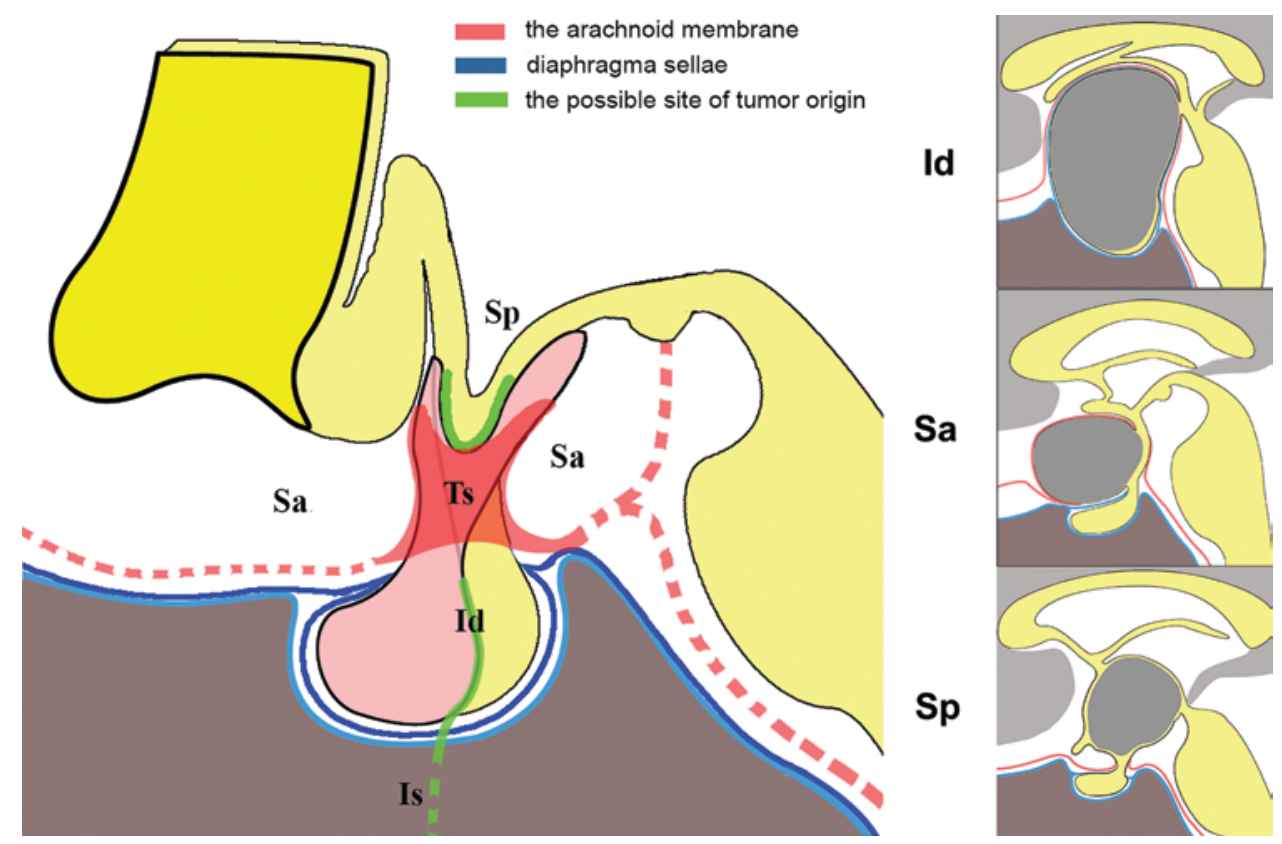

FIG. 1. The diagram shows the anatomical basis of our classification system. Left: The pituitary stalk penetrates the basal arachnoid membrane (BAM) covering diaphragma sellae where the BAM extends upward along the pituitary stalk, which forms an arachnoid sleeve (pink dotted line) to envelop the pituitary stalk. The stalk can therefore be divided into 3 segments according to its relationship with the surrounding arachnoid membrane: infraarachnoid (subdiaphragmatic) segment, intraarachnoid segment (within the arachnoid sleeve of the pituitary stalk), and subarachnoid segment. CPs arising from the pituitary stalk will have a different topographic relationship with these membranous structures. Theoretically, CP developing along the pituitary stalk has 5 basic growth patterns based on the tumor's anatomical locations and topographic relationships with the seller meningeal structures: 1) pattern Id, infradiaphragmatic growth (extraarachnoid); 2) pattern Ts, transstalk growth (intraarachnoid); 3) pattern Sa, suprasellar subarachnoid extraventricular growth (subarachnoid extrapial); 4) pattern Sp, subarachnoid subpial ventricular growth (subpial); and rarely, 5) pattern Is, infrasellar growth (extraarachnoid). Right: The growth of CPs can be broadly divided into 3 basic groups: 1) infradiaphragmatic (Id), 2) subarachnoid extraventricular (Sa), and 3) subpial intraventricular (Sp). Each tumor group can develop complex subsets along the hypothalamopituitary axis during tumor development. These growth pattern variants could be interpreted by the 5 basic growth patterns. Figure is available in color online only. 
TABLE 1. Growth patterns and tumor-meningeal relationships in 226 patients with primary CP, according to our classification scheme

\begin{tabular}{|c|c|c|c|c|c|c|c|}
\hline \multirow{2}{*}{$\begin{array}{l}\text { Possible Site of } \\
\text { Tumor Origin }\end{array}$} & \multirow[b]{2}{*}{ Classification } & \multirow[b]{2}{*}{ Classic Name of CP } & \multirow[b]{2}{*}{ Growth Pattern } & \multirow[b]{2}{*}{ Tumor-Arachnoidal Relationship } & \multicolumn{2}{|c|}{ Patients } & \multirow[b]{2}{*}{ Total } \\
\hline & & & & & Juveniles & Adults & \\
\hline \multirow[t]{4}{*}{ Infradiaphragmatic } & \multirow[t]{4}{*}{ Group I (Id-CP) } & Infrasellar CP & Purely Is or Is+ld & Extraarachnoidal & 9 & 0 & \multirow[t]{4}{*}{62} \\
\hline & & Infradiaphragmatic CP & Id & Extraarachnoidal & 32 & 10 & \\
\hline & & Transdiaphragmatic CP & Id+Ts & Extra-, intraarachnoidal combined & 7 & 0 & \\
\hline & & Transstalk CP & $I d+T s+S p$ & $\begin{array}{l}\text { Extra-, intra-, subarachnoidal } \\
\text { combined }\end{array}$ & 0 & 4 & \\
\hline \multirow{4}{*}{$\begin{array}{l}\text { Supradiaphragmatic } \\
\text { infundibulum }\end{array}$} & \multirow[t]{2}{*}{ Group II (Sa-CP) } & \multirow{2}{*}{$\begin{array}{l}\text { Suprasellar extraventricu- } \\
\quad \text { lar CP }\end{array}$} & Sa1 (prestalk) & \multirow[t]{2}{*}{ Subarachnoidal, extrapial } & 1 & 34 & \multirow[t]{2}{*}{46} \\
\hline & & & Sa2 (retrostalk) & & 7 & 4 & \\
\hline & \multirow[t]{2}{*}{ Group III (Sp-CP) } & Intraventricular CP & Purely Sp & Subarachnoidal, subpial & 7 & 44 & \multirow[t]{2}{*}{118} \\
\hline & & Intra-, extraventricular CP & $\mathrm{Sp}+\mathrm{Ts}$ or $\mathrm{Sp}+\mathrm{Sa}$ & $\begin{array}{l}\text { Subarachnoidal, intra-, extrapial } \\
\text { combined }\end{array}$ & 33 & 34 & \\
\hline Total & & & & & 96 & 130 & 226 \\
\hline
\end{tabular}

originated within the infrasellar and/or intrasellar cavity below the diaphragm and arachnoid. The emergence of the tumor caused upward displacement of the sellar diaphragm and arachnoid. In juveniles, the tumor may originate more deeply from the infrasellar region, which includes the pharynx, sphenoidal sinus, and ethmoid sinus. In rare cases, the tumor may expand longitudinally up through the diaphragm along the pituitary stalk and dilate the suprasellar portion of the pituitary stalk (Fig. $2 b)$. In addition, suprasellar expansion of the tumor could extrude the covering of the sellar diaphragm, resulting in secondary cysts to the tumor capsule dome. In contrast, Id-CP in adult patients never involved the infrasellar region but rather usually emerged as purely intrasellar or intrasellar/suprasellar masses. Few adult cases showed tumor involvement along the whole length of the pituitary stalk (transstalk growth; Fig. 2c). These tumors probably originated in the sella turcica and expanded up through the diaphragm along the pituitary stalk and were thus assigned to the Id-CP group.

\section{Group II: Sa-CPs}

From its point of origin on the proximal stalk and infundibulum region, Sa-CPs mainly developed freely in the suprasellar subarachnoid spaces. Extraventricular tumor development was either prestalk (Fig. 3) or retrostalk
(Fig. 4), depending on the orientation of tumor expansion. The main body of the tumor was separated from the surrounding structures by the suprasellar arachnoid around the pituitary stalk, except at the proximal portion of the pituitary stalk (infundibulum area), where the tumor had a subpial relationship with the stalk. The infundibulum area may also be a site of tumor origin. Tumors with a suprasellar subarachnoid extraventricular growth pattern tended to occupy multiple compartments due to tumor expansion along the subarachnoid cisterns, especially in pediatric patients (Fig. 5).

\section{Group III: Sp-CPs}

Sp-CPs represented the most complicated growth pattern. This group of tumors initially grew around the infundibulotuberal region (the subarachnoid segment of the pituitary stalk) and the top portion of the hypothalamopituitary tract. Growing tumors mainly occupied the third ventricle cavity and were actually enclosed within the thinning nerve tissue of the third ventricle walls (usually within the TVF). These tumors corresponded to subpial lesions and were thus enclosed within the thinning nervous tissues of the TVF and separated from the suprasellar cistern by a layer of pia mater. The tumors were in direct contact with the neural tissue of the third ventricle wall, making the attachments of the tumor to the hypo-

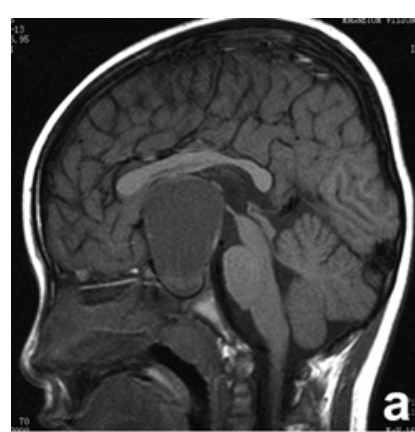

pattern "Id"

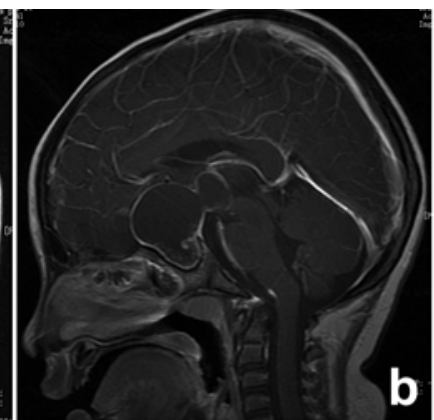

pattern "Id+Ts"

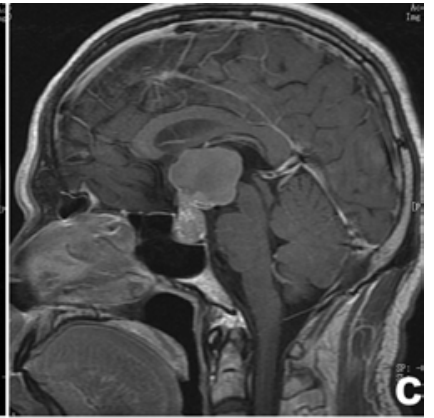

pattern "Id+Ts+Sp"

FIG. 2. The basic (pattern Id) and variant (pattern Is+Id [not shown here]; Id+Ts; and Id+Ts+Sp) growth patterns in CPs with an infradiaphragmatic origin. The tumor maintains an extraarachnoid location in both pattern Id (a) and/or Is+ld. Rarely, growing tumor may expand along the pituitary stalk, making the tumor's anatomical locations either extra- and intraarachnoid combined (pattern Id+Ts; b) or extra-, intra-, and subarachnoid subpial (pattern Id+Ts+Sp; c). 


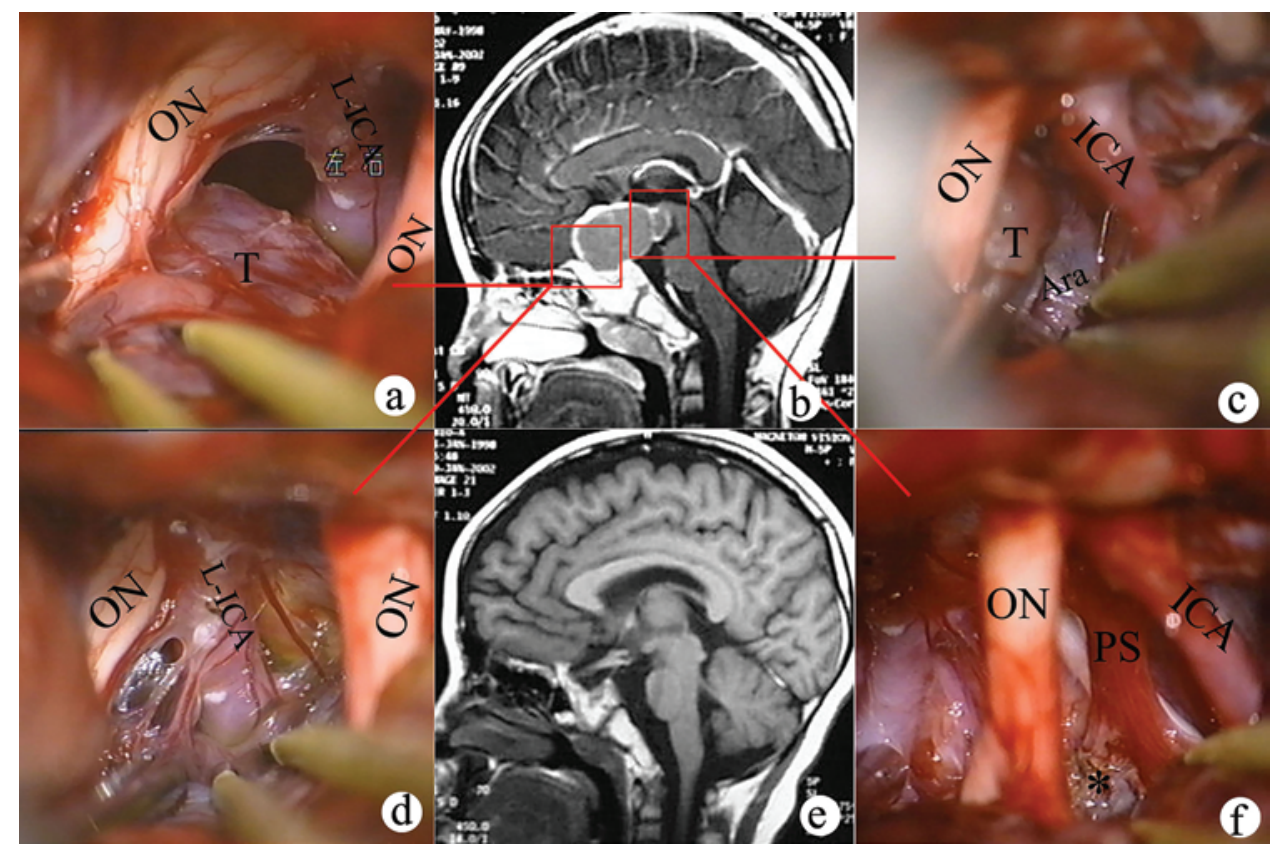

FIG. 3. Pre- and postoperative sagittal T1-weighted MR images ( $b$ and e) and intraoperative pictures (a, $c$, $d$, and f) in a suprasellar subarachnoid extraventricular CP (Group II, Sa-CP) with growth pattern Sa1. The tumor arises from the pituitary stalk and mainly localizes inside the optical chiasm cistern. Dissection of the tumor is mainly accomplished through the prechiasm space ( $a$ and d). The tumor can be dissected along its own arachnoid dissecting plane from the chiasm, TVF, and the main arteries, except at the site of the tumor origin where the tumor needs sharp dissecting ( $c$ and $\mathrm{f}$ ). Postoperative MRI showed total removal of tumor by the right pterion approach (e). Note the site of the tumor origin at the proximal end of the pituitary stalk (asterisk, f). Ara $=$ arachnoid around the pituitary stalk; ICA = internal carotid artery; L-ICA = left ICA; ON = optic nerve; PS = pituitary stalk; T = tumor. Figure is available in color online only.

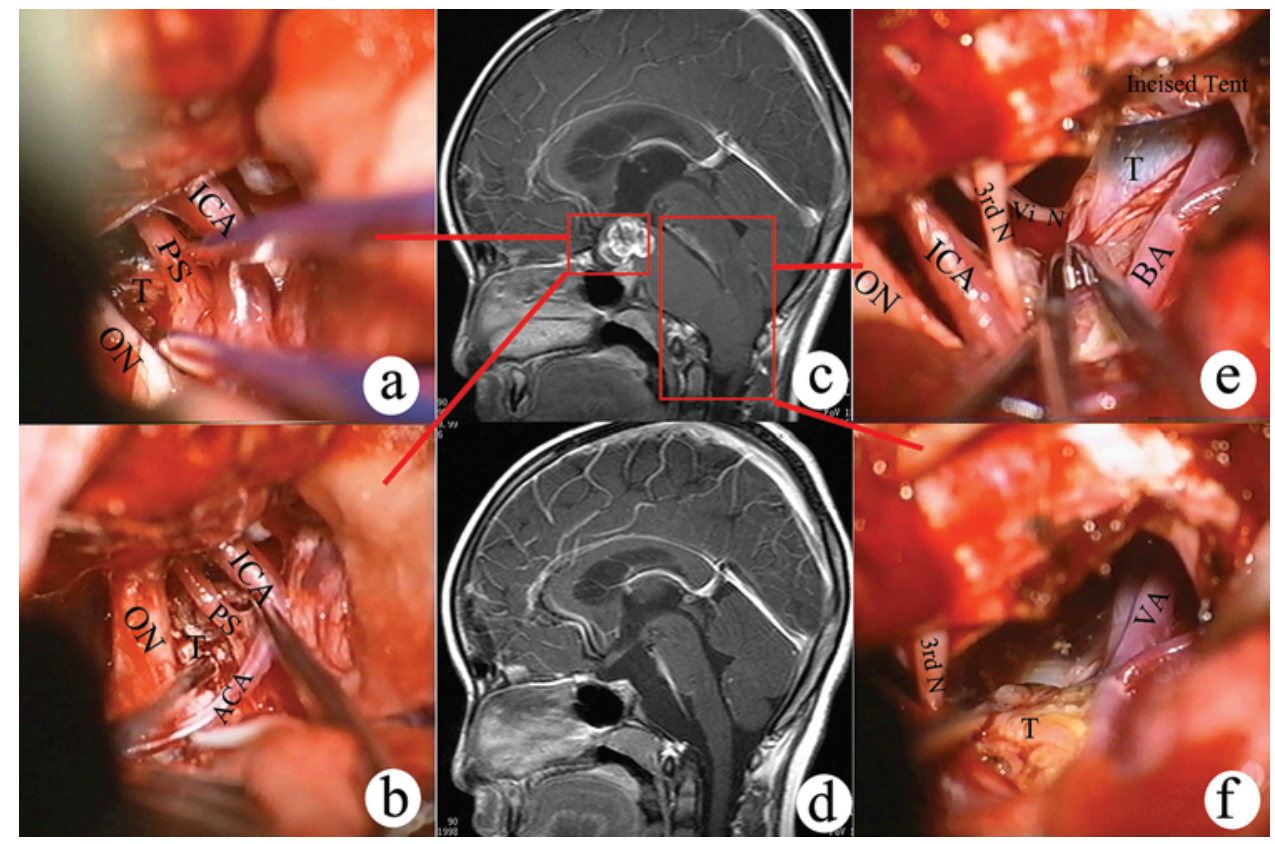

FIG. 4. Pre- and postoperative MR images (c and d) and intraoperative pictures (a, b, e, and f) demonstrating a large subarachnoid extraventricular CP (Group II, Sa-CP) with retrostalk extension (pattern Sa2). From the origin site at the chiasmatic cistern around the pituitary stalk, the tumor capsule extended mainly into the retroclivus cistern and finally involved the posterior cranial fossa and cervical spinal canal (c). The tumor was removed by a right frontotemporal transtentorial approach. Intraoperative photos show the various aspects of the tumor: the tumor adhered tightly to the TVF and the pituitary stalk (a). Only at the proximal portion of the pituitary stalk and infundibulum does the tumor have a subpial relationship with the nerve tissue (b). Dissection of the tumor capsule should trace the arachnoid plane under direct vision (e and f). Postoperative MR image shows the total removal of tumor (d). 3rd N = oculomotor nerve; $\mathrm{ACA}$ = anterior cerebral artery; BA = basal artery; Tent = tentorium; VA = vertebral artery; $\mathrm{Vi} \mathrm{N}=$ abducens nerve. See Fig. 3 for additional abbreviations. Figure is available in color online only. 


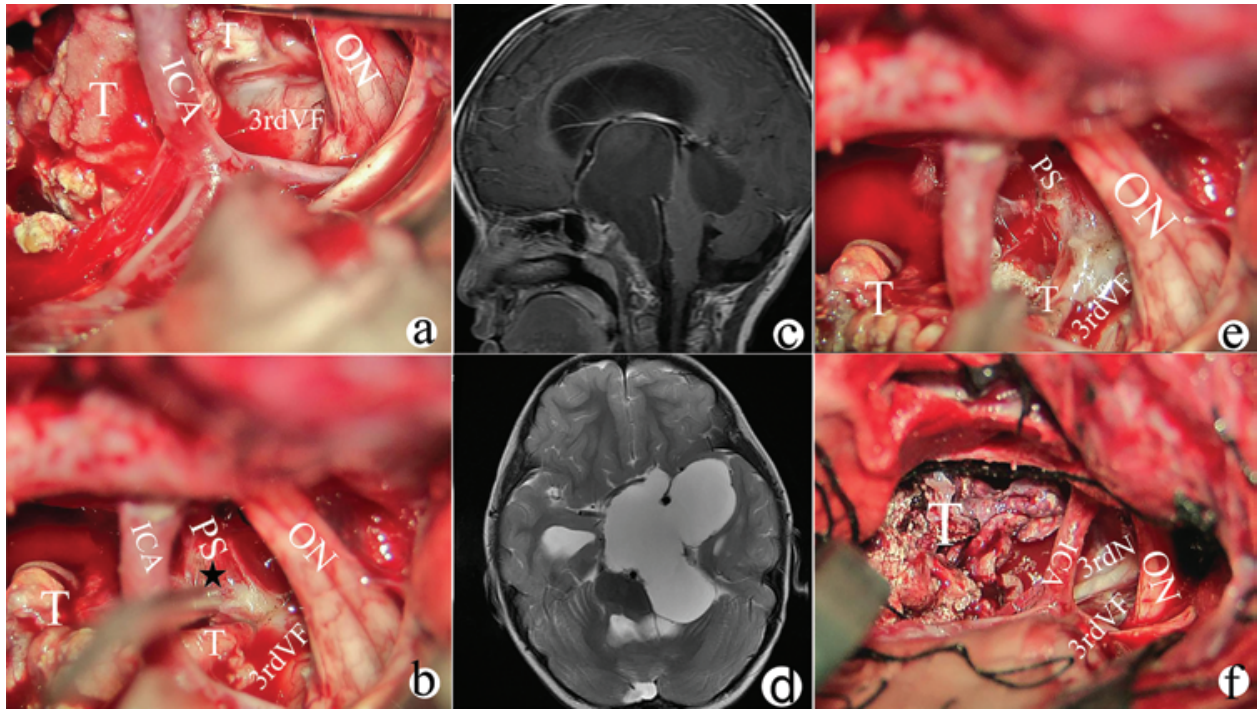

FIG. 5. Preoperative MR and CT scans ( $\mathbf{c}$ and $\mathbf{d})$ and intraoperative pictures (a, b, e, and f) demonstrating a huge subarachnoid extraventricular cisternal CP (Group II, Sa-CP) with retrostalk extension (pattern Sa2). From the origin site at the chiasmatic cistern around the pituitary stalk, the tumor capsule expanded along the subarachnoid space and significantly compressed the TVF by extending into the adjacent basal cistern and finally involved multiple cisterns. The tumor was removed via a left-sided frontotemporal combined supra- and infratentorial approach. Intraoperative photos show the various aspects of the tumor: the tumor adhered tightly to the TVF but without infiltrating it ( $a, b$, and e). Only at the proximal portion of the pituitary stalk and infundibulum (star, b) does the tumor have subpial adherences with the nerve tissue. 3rd $\mathrm{N}=$ oculomotor nerve (contralateral in this case); 3rd $V F=3$ rd ventricle floor. See Fig. 3 for additional abbreviations. Figure is available in color online only.

thalamus and optic tract structures more tenacious. The anteroinferior portion of the third ventricle usually manifested frog-belly expansion, and the remaining pituitary stalk could be seen compressed inferior to the tumor (Fig. 6). Global extension of the tumor along the pituitary stalk dilated the distal part of the stalk and severely distended the stalk and its overlying arachnoid membrane to form an external tumor capsule (Fig. 7); this made dissection of the tumor from the hypothalamopituitary tract even more difficult and dangerous. In rare cases, progressive growth caused the low pole of the tumor to penetrate the gray matter of the infundibulotuberal area; therefore, the tumor was located both outside and inside the third ventricle cavity (Fig. 8). Radical removal of these tumors will inevitability result in defects of the anteroinferior portion of the TVF.

\section{Correlation Between Tumor Growth Patterns and Pathological Features}

All pediatric tumors were classified as adamantinomatous craniopharyngioma (ACP), while in adults $21.5 \%$ of tumors (28/130) were typical squamous papillary craniopharyngioma (PCP). The median age of patients with PCP was 38 years (range 19-72 years), and the median age of patients with ACP was 24 years (range 2-66 years). Infradiaphragmatic tumors were always adamantinomatous, while $28(17 \%)$ of the suprasellar tumors were typical PCP. Among these 28 tumors, 23 (82.1\%) belonged to Group III.

\section{Differences in CP Growth Patterns Between Childhood and Adult Cases}

Classification of the 226 patients with $\mathrm{CP}$ is shown in

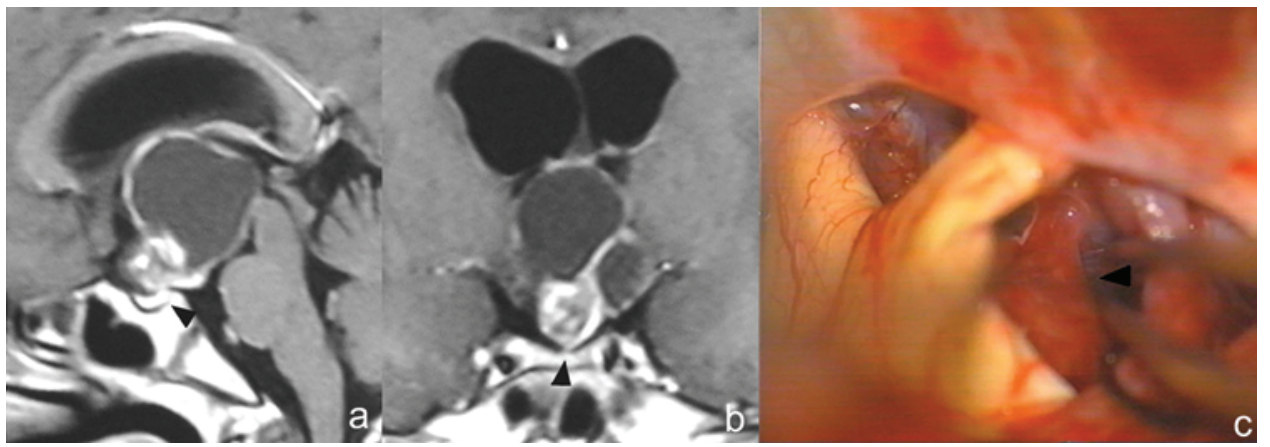

FIG. 6. Sagittal (a) and coronal (b) contrast-enhanced T1-weighted MR images obtained before surgery and intraoperative photo (c) obtained in a 6-year-old girl with a typical Sp-CP (Group III, purely Sp growth pattern). Note the inferiorly compressed pituitary stalk (black arrowhead, a and b). Intraoperative picture showing the frog-belly-like inflated anterior part of the third ventricle (black arrowhead, c) and a suprasellar cistern that is free of tumor. The tumor was a subpial lesion and was actually embedded within the thinning nerve tissue of the TVF. Figure is available in color online only. 


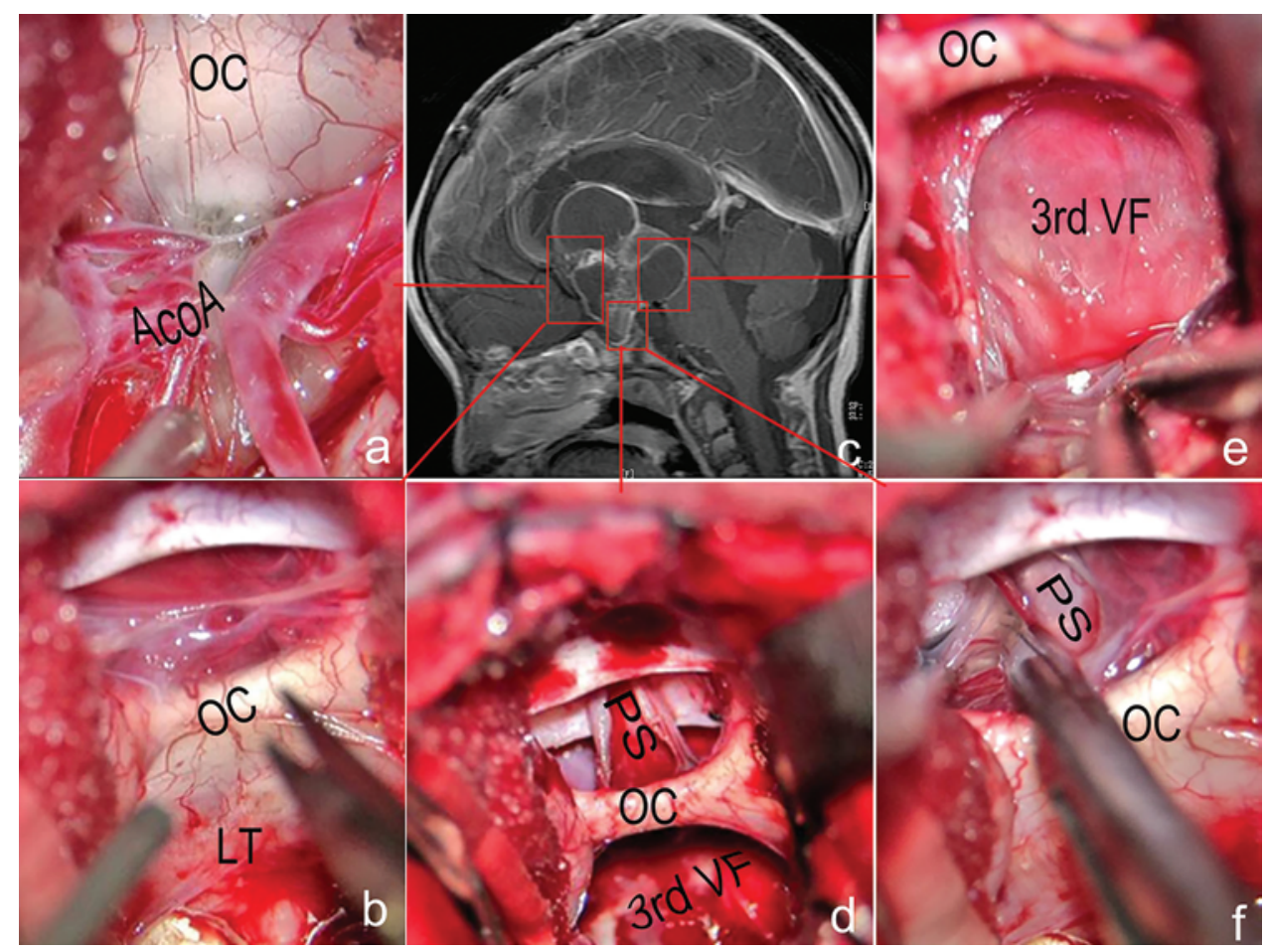

FIG. 7. Preoperative MR image and intraoperative photos obtained in a 7-year-old boy with a typical infundibulotuberal CP (Group III, Sp-CP) with a growth pattern of Sp+Ts. The boy underwent an emergency procedure via the transcorpus callosum transfornix approach to alleviate the hydrocephalus before tumor removal. Sagittal contrast-enhanced T1-weighted MR image (c) shows a large cystic-solid mixed CP mainly occupying the third ventricle chamber. The inferiorly compressed pituitary stalk and normal gland could be identified at the bottom of the tumor. Intraoperative pictures show removal of the tumor. The bulgy lamina terminalis $(\mathrm{LT})$ has been exposed after dividing the ACoA ( $\mathbf{a}$ and $\mathbf{b}$ ). After dissection of the arachnoid enveloping the pituitary stalk, the bulged pituitary stalk was exposed (f). The tumor was totally removed via the combination of a trans-LT and extraaxial route. The pituitary stalk was split vertically to expose the tumor (d). Note the attenuated but uninterrupted TVF after tumor removal (e). ACoA $=$ anterior communicating artery; $\mathrm{OC}=$ optic chiasm. See Figs. 3 and 5 for additional abbreviations. Figure is available in color online only.

Table 1. CP growth patterns were significantly different between childhood- and adult-onset tumors $(\mathrm{p}=0.024)$.

\section{Group I}

Id-CPs were predominantly observed in children and were uncommon in adults (48/96 children [50\%] vs 14/130 adults [10.7\%]). Juvenile Id-CPs cases differed from adult cases in terms of tumor size, anatomical location, tumor expansion pattern, and cavernous sinus involvement (Table 2). The topographic features of juvenile Id-CPs indicated that they were more invasive than adult Id-CPs. In addition, juvenile Id-CPs had broad sites of origin, ranging from the nasopharynx to the junction of the pituitary gland and stalk, whereas adult Id-CPs had higher and more specific sites of origin within the pituitary fossa.

\section{Group II}

Sa-CPs were commonly observed in adults but were rare in children (38/130 adults [29.2\%] vs $8 / 96$ children [8.3\%]; Table 1). Furthermore, adult-onset Sa-CPs usually emerged as a prestalk growth, whereas childhood-onset tumors tended to expand into the retroclivus and posterior fossa.

\section{Group III}

Sp-CPs involving the third ventricle walls occurred at a higher rate in adults than in children (78/130 adults [60\%] vs 40/96 children [42\%]). The trend persisted when only adamantinomatous Sp-CPs (ACPs) were compared between children and adults (51\% for adults vs $42 \%$ for children); however, this difference did not reach statistical significance $(p=0.24)$. Further analysis of the tumor growth pattern showed that tumors in adult patients with $\mathrm{Sp}-\mathrm{CP}$ appeared to exhibit a purely subarachnoid subpial ventricular growth pattern (44/78 [56\%]), whereas tumors in children tended to exhibit a combination of transstalk and subarachnoid subpial ventricular growth (28/40 [70\%]).

\section{Clinical Relevance of Tumor Growth Patterns}

Patient symptoms at presentation were closely related to tumor growth patterns (Table 3). Sixty-four percent of patients sought medical attention because of visual compromise; this correlated to $88.7 \%$ of Id-CP patients, $76.1 \%$ of Sa-CP patients, and $45.8 \%$ of Sp-CP patients ( $<<0.001)$. In addition, patients with Id-CPs were more likely to have pituitary dysfunction; this was particularly true in juvenile patients, as $38.7 \%$ of children with Id-CPs had panhypopituitarism on admission. Diabetes insipidus, which represents the effect of the tumor on the pituitary stalk, occurred in $41.9 \%$ of patients with Id-CPs, $13 \%$ of patients with $\mathrm{Sa}-\mathrm{CPs}$, and $12.8 \%$ of patients with $\mathrm{Sp}-\mathrm{CPs}(\mathrm{p}<$ 


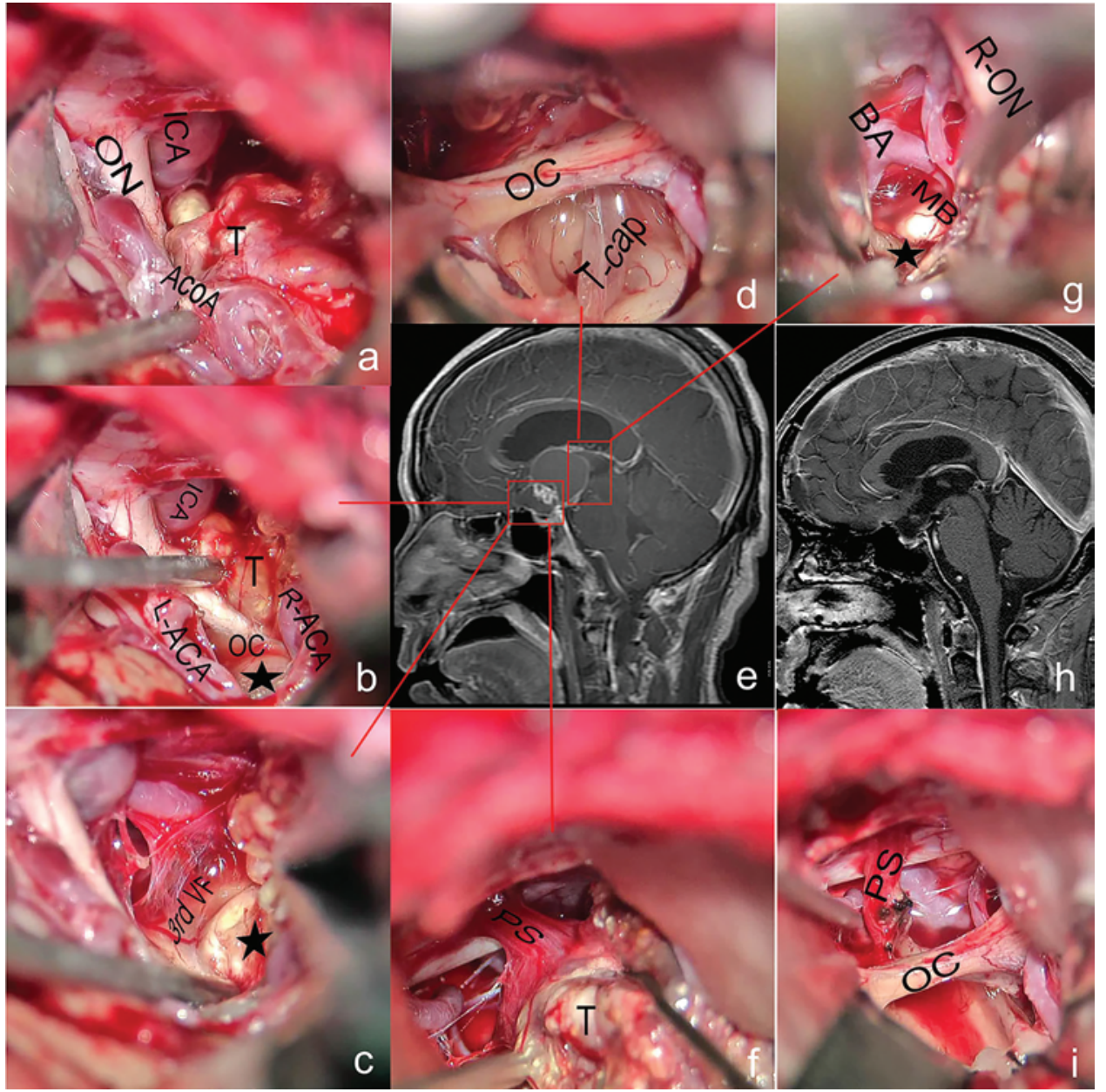

FIG. 8. Pre- and postoperative MRI and intraoperative photos obtained in a 58-year-old man with a typical infundibulotuberal CP (Group III, Sp-CP) with a growth pattern of Sp+Sa. Preoperative sagittal contrast-enhanced T1-weighted MR image (e) shows a lobulated cystic-solid mass mainly occupying the third ventricle chamber at the suprasellar region. Intraoperative pictures reveal the growth pattern of the tumor. Having originated from the infundibulotuberal part of the TVF, the tumor was located partially outside and partially inside of the third ventricle cavity. The extraventricular part of the tumor has an arachnoid interface to the chiasm and ACOA (a and b), and the bulgy LT has been exposed after dissection of the tumor's extraventricular part (star, b). Note a flying saucer-shaped expansion of the tumor (star, c) through the infundibulotuberal region of the TVF. The posterosuperior tumor cyst invaginated into the gray matter (tuber cinereum [star], g) of the TVF (d). Involvement pattern of the pituitary stalk (f). Postoperative sagittal contrast-enhanced T1-weighted MR image (h) and intraoperative photo (i) show total removal of the tumor and disturbance of the TVF. MB = mammillary body; T-cap = tumor capsule. See previous figures for additional abbreviations. Figure is available in color online only.

0.001). In contrast, symptoms related to increased intracranial pressure and nonspecific headaches occurred more frequently in patients with $\mathrm{Sp}-\mathrm{CPs}$ than in those with other types of tumor growth $(\mathrm{p}<0.001)$. Hydrocephalus rarely occurred in Group I (8\%) and Group II (13\%) but was commonly observed in Group III (65.3\%, including 34\% with severe hydrocephalus and marked ventricular widening and/or periventricular edema; $p<0.0001$; Table 3). Apart from a slightly higher percentage of coarse calcification in tumors in Group III, there were no significant differences in tumor size and tumor components among the 3 groups.

\section{Surgical Details}

Operative Approaches

Operative approaches were directly related to the growth pattern of the tumor. Surgical removal of both Group I and Group II tumors was accomplished by an extraaxial route, which included pterional, frontobasal interhemispheric, or transsphenoidal approaches. A translamina terminalis route was used in all Group III patients, either alone or in combination with other extraaxial routes. We favored midline transcranial approaches to the lamina terminalis, particularly the anterior interhemispheric route, which avoids the disadvantages of anterolateral approaches (e.g., lack of visualization of the ipsilateral wall of the third ventricle and hypothalamus, limited oblique visualization superiorly into the third ventricle, limited visualization inferiorly into the interpeduncular cistern, and narrowing of the lamina terminalis working corridor). The anterior communicating artery was severed for better tumor exposure in some large tumors. 
TABLE 2. Differences in anatomical locations of Id-CPs between juvenile and adult patients

\begin{tabular}{|c|c|c|}
\hline Parameter & Juveniles (48 patients, $50 \%$ [48/96] of the pediatric age group) & Adults (14 patients, $11 \%$ [14/130] of the adult group) \\
\hline Mean lesion size in $\mathrm{cm}^{*}$ & $4.39 \pm 1.52$ & $2.75 \pm 1.09$ \\
\hline \multirow[t]{4}{*}{ Tumor's anatomical location } & Pattern Is: 1 case (purely infrasellar) & \\
\hline & Pattern Is+ld: 8 cases (infra-, intra-, suprasellar, infradia) & \\
\hline & Pattern Id: 32 cases (intra-, suprasellar, infradia) & Pattern Id: 10 cases (intrasellar, infradia, suprasellar) \\
\hline & Pattern Id+Ts: 7 cases (intra-, suprasellar, transtalk) & $\begin{array}{l}\text { Pattern Id+Ts+Sp: } 4 \text { cases (intra-, suprasellar, } \\
\text { transinfundibulum) }\end{array}$ \\
\hline $\begin{array}{l}\text { Secondary cysts after break } \\
\text { through the diaphragm }\end{array}$ & 11 cases $(23 \%)$ & None \\
\hline Involvement of cavernous sinus & 2 cases $(4 \%$, rare $)$ & None \\
\hline Possible origin site & $\begin{array}{l}\text { From the nasopharynx to the junction of the pituitary gland \& } \\
\text { the stalk }\end{array}$ & $\begin{array}{l}\text { Intrasellar portion of pituitary stalk near foramen } \\
\text { diaphragmatis }\end{array}$ \\
\hline
\end{tabular}

Infradia = infradiaphragmatic.

* There was statistical significant difference between children and adults $(p<0.001)$.

\section{Extent of Tumor Removal}

The gross-total removal rate was highest in Group II (95.6\%), followed by Group I (82.3\%). In contrast, the gross-total removal rate in Group III was $67 \%$. This difference in tumor removal rate between groups was significant ( $\mathrm{p}<0.001)$. In most patients, any residual tumor was minor on postoperative MRI, and solid tumors were observed in only 7 patients.

\section{Perioperative Care and Surgical Complications}

During the early postoperative period, hypothalamicpituitary axis dysfunction, including water and electrolyte disorders, were commonly observed. Therefore, daily measurements of plasma sodium and accurate fluid balance charts were essential to assess the need for continued treatment. Forty patients (17.6\%) experienced a medical or surgical complication. A second surgical intervention was necessary in 11 patients (decompression procedures in 4 patients, evacuation of an epidural hematoma in 2, cerebrospinal shunt placement in 6 , evacuation of a subdural hematoma in 1, and exclusion of an opened frontal sinus responsible for a cerebrospinal leakage in 1 [some patients had more than one procedure]). Perioperative mortality was $3.98 \%$ (9 patients) in the entire series, and all cases occurred in Group III patients (Table 4). Although the events associated with operative mortality are multifactorial, a few were found to be major contributors, including

TABLE 3. Clinical presentation and neuroimaging data for 226 patients with primary CPs based on tumor growth patterns

\begin{tabular}{|c|c|c|c|c|c|}
\hline Parameter & Total & Id-CPs & Sa-CPs & Sp-CPs & $p$ Value \\
\hline No. of patients & & 62 & 46 & 118 & \\
\hline Age & & & & & $<0.001$ \\
\hline Children ( $\leq 16$ yrs) & 96 & 48 & 8 & 40 & \\
\hline Adults (>16 yrs) & 130 & 14 & 38 & 78 & \\
\hline \multicolumn{6}{|l|}{ Sex } \\
\hline Male & 145 & 43 & 25 & 77 & \\
\hline Female & 81 & 19 & 21 & 41 & \\
\hline \multicolumn{6}{|l|}{ Preop symptoms } \\
\hline Visual disturbance & $63.7 \%$ & $88.7 \%$ & $76.1 \%$ & $45.8 \%$ & $<0.001$ \\
\hline Headache & $53.5 \%$ & $43.7 \%$ & $30.4 \%$ & $66.9 \%$ & $<0.001$ \\
\hline Pituitary function & & & & & $<0.001$ \\
\hline Normal & $15.9 \%$ & $12.9 \%$ & $23.9 \%$ & $14.4 \%$ & \\
\hline Partial hypopituitarism & $60 \%$ & $48.4 \%$ & $67.4 \%$ & $63.6 \%$ & \\
\hline Pan-hypopituitarism & $24 \%$ & $38.7 \%$ & $8.7 \%$ & $20 \%$ & \\
\hline DI & $21.1 \%$ & $41.9 \%$ & $13 \%$ & $12.8 \%$ & 0.032 \\
\hline \multicolumn{6}{|l|}{ Neuroimaging } \\
\hline Tumor size $(\mathrm{cm})$ & $3.83 \pm 1.26$ & $4.0 \pm 1.55$ & $3.59 \pm 1.68$ & $3.84 \pm 0.83$ & 0.243 \\
\hline \multirow[t]{2}{*}{ Hydrocephalus } & None $(61 \%, 138 / 226)$ & 57 & 40 & 41 & $<0.001$ \\
\hline & Yes $(39 \%, 88 / 226)$ & 5 & 6 & 77 & \\
\hline
\end{tabular}


TABLE 4. Summary of perioperative mortality in 226 patients with primary CP

\begin{tabular}{|c|c|c|c|c|c|c|c|}
\hline $\begin{array}{l}\text { Case } \\
\text { No. }\end{array}$ & $\begin{array}{l}\text { Age } \\
\text { (yrs), } \\
\text { Sex }\end{array}$ & $\begin{array}{l}\text { Size }(\mathrm{cm}) \& \\
\text { Component of } \\
\text { Tumor }\end{array}$ & Type & Approach & $\begin{array}{l}\text { Assessment } \\
\text { of Removal }\end{array}$ & Events & $\begin{array}{l}\text { Death From } \\
\text { Time of Op } \\
\text { (days) }\end{array}$ \\
\hline 1 & $6, F$ & 7 & $\mathrm{Sp}-\mathrm{CP}$ & AlH & Total & $\begin{array}{l}\text { Seizures, pan-hypopituitarism, severe hypothalamic dysregulation } \\
\text { (hyperpyrexia, hypernatremia, DI), peritonitis of undetermined } \\
\text { cause }\end{array}$ & 12 \\
\hline 2 & $11, F$ & $\begin{array}{l}5, \text { massive } \\
\text { calcification }\end{array}$ & $\mathrm{Sp}-\mathrm{CP}$ & AlH & Subtotal & $\begin{array}{l}\text { Frontal contusion, decompression procedure, severe hypotha- } \\
\text { lamic dysregulation, acute pulmonary edema }\end{array}$ & 5 \\
\hline 3 & $27, \mathrm{~F}$ & $\begin{array}{l}\text { 4.5, massive } \\
\text { calcification }\end{array}$ & $\mathrm{Sp}-\mathrm{CP}$ & FT & Subtotal & $\begin{array}{l}\text { Intraop brain swelling, hypothalamic infarction, VP shunt, severe } \\
\text { hypothalamic dysregulation }\end{array}$ & 127 \\
\hline 4 & $30, \mathrm{M}$ & 4 & $\mathrm{Sp}-\mathrm{CP}$ & FT & Total & $\begin{array}{l}\text { Evacuation of epidural hematoma, ischemia in area of perforating } \\
\text { vessels, dehydration \& cerebral collapse due to hypothalamic } \\
\text { failure }\end{array}$ & 13 \\
\hline 5 & $9, F$ & 4 & $\mathrm{Sp}-\mathrm{CP}$ & FT & Total & Seizures, ventricle hematoma, external drainage & 90 \\
\hline 6 & $34, F$ & 3.5 & $\mathrm{Sp}-\mathrm{CP}$ & FT & Subtotal & $\begin{array}{l}\text { Intraop brain swelling, frontal contusion, decompression proce- } \\
\text { dure, severe hypothalamic dysregulation }\end{array}$ & 5 \\
\hline 7 & $19, \mathrm{M}$ & 3 & Sp-CP & FT & Total & $\begin{array}{l}\text { Anorexia \& significant weight loss, dehydration \& cerebral col- } \\
\text { lapse due to hypothalamic failure, pulmonary emboli }\end{array}$ & 65 \\
\hline 8 & $23, \mathrm{M}$ & $\begin{array}{l}\text { 5, massive } \\
\text { calcification }\end{array}$ & $\mathrm{Sp}-\mathrm{CP}$ & FT & Total & $\begin{array}{l}\text { Ischemia in area of perforating vessels, severe hypothalamic } \\
\text { dysregulation (hyperpyrexia, hypernatremia, DI), pulmonary } \\
\text { infection }\end{array}$ & 22 \\
\hline 9 & $54, \mathrm{M}$ & $\begin{array}{l}\text { 4, massive } \\
\text { calcification }\end{array}$ & Sp-CP & AlH & Total & $\begin{array}{l}\text { Tear of left ACA, hypothalamic infarction, severe hypothalamic } \\
\text { dysregulation (hyperpyrexia, hypernatremia, DI) }\end{array}$ & 8 \\
\hline
\end{tabular}

$\mathrm{AlH}=$ anterior interhemispheric approach; $\mathrm{FT}$ = frontotemporal approach; $\mathrm{VP}=$ ventriculoperitoneal.

cerebral vascular injury (both major cerebral artery and small perforating vessels), attempted radical resection for massive calcifications, intraoperative brain swelling, and related postoperative severe hypothalamic dysfunction.

\section{Postoperative Weight Gain and Hypothalamic Status}

All but 8 surviving patients were followed up for a minimum of 3 months. The mean follow-up period was $75 \pm 42.3$ months (range 3-184 months). Data on postoperative weight gain were available for 60 patients $(97 \%)$ with Id-CPs, 46 patients (100\%) with Sa-CPs, and 102 patients (94\%) with Sp-CPs. There was a trend toward greater mean postoperative weight gain both in children and in adults within Group III as compared with the other 2 groups ( $\mathrm{p}<0.001$; Fig. 9). Over the first 2 postopera- tive years, $41.7 \%$ of children and $16.7 \%$ of adults with $\mathrm{Sp}$ CPs had significant weight gain (BMI greater than +4 SDs for children or BMI > 30 for adults). The relevant rates of weight gain in children and adults were $2.2 \%$ and $7.1 \%$ for patients with Id-CPs and $12.5 \%$ and $2.6 \%$ for patients with Sa-CPs, respectively.

The HSS of surviving patients was evaluated at least 3 months after the initial surgery (Fig. 10). Patients in Groups I and II showed a better hypothalamic status than those in Group III, with a Grade 1 hypothalamic status (normal hypothalamic function) observed in $57 \%$ and $43 \%$ of patients in Groups I and II, respectively. Patients in Group III had more severe hypothalamic reactions, with $39 \%$ of patients rated as having Grade 3 or 4 hypothalamic status in the first 2 postoperative years $(\mathrm{p}<0.001)$.
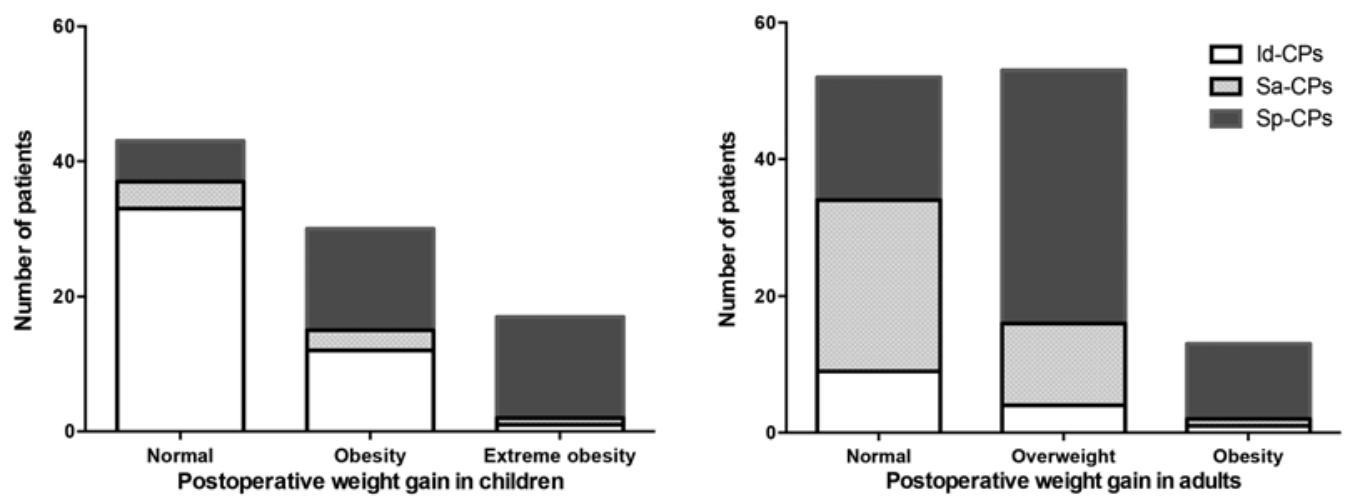

FIG. 9. Histograms summarizing postoperative weight gain in patients with childhood-onset (left) and adult-onset (right) CPs based on tumor growth patterns. 


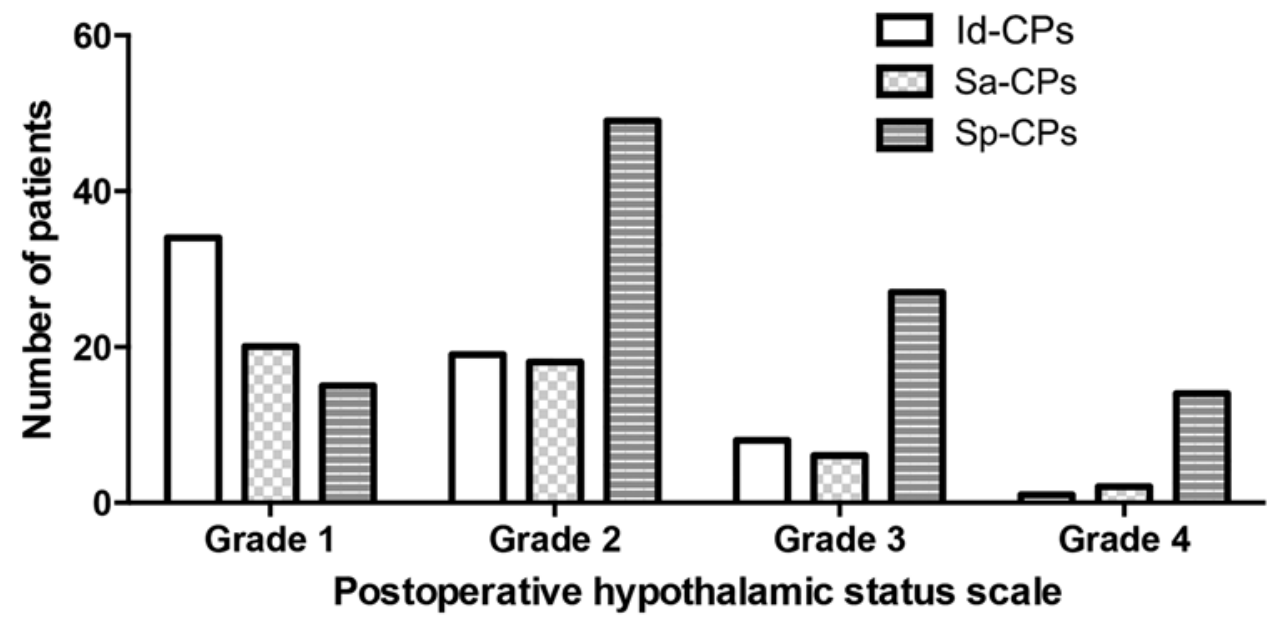

FIG. 10. Histograms summarizing postoperative HSS scores based on tumor growth patterns.

\section{Recurrence and Adjuvant Therapies}

Tumor recurrence, defined as evidence of tumor growth on neuroimaging with or without clinical symptoms, occurred in 52 patients within 1-11 years (median 2 years) after initial surgery. The recurrence rate after complete resection was $16.4 \%$. The PFS rates for all patients after 2, 5, and 10 years were $82 \%, 72 \%$, and $64 \%$, respectively. In 2 patients with Id-CPs, the recurrent tumors were restricted to the pituitary fossa; these 2 patients have not yet been surgically treated because of their stable visual and neurological status. Most patients with recurrent Id-CP were treated with reoperation, while patients with recurrent SpCPs were more likely to be treated with radiation therapy. In our institution, we typically use external beam radiation therapy as salvage radiation therapy for unresectable recurrent CP. Gamma Knife surgery was prescribed for small and early-detected cases of recurrence at the crucial hypothalamic area. Four patients died after their first tumor recurrence, 16 of the 46 surviving patients experienced a second recurrence, and 5 ultimately died of uncontrolled disease. Notably, none of the 7 patients who underwent Gamma Knife surgery experienced tumor re-progression during 1-5 years (median 2 years) of follow-up.

\section{Survival}

The median follow-up period was 78 months (range 6-184 months) for Group I, 75 months (range 12-176 months) for Group II, and 56 months (range 3-168 months) for Group III. The overall tumor-related mortality rate in our series was $11.5 \%$ ( 25 of 217 patients). There were 9 perioperative deaths, all of which occurred in Group III. The OS rate for all patients was $92 \%$ at 5 years and $87 \%$ at 10 years. No death was observed after 11 postoperative years. The 5- and 10-year OS rates were $95 \%$ and $89 \%$ for patients in Group I, 95\% and 92\% for those in Group II, and $87 \%$ and $81 \%$ for those in Group III, respectively. The most common causes of follow-up mortalities in Group I were long-term severe endocrinopathy, such as pan-hypopituitarism; most of the mortalities in Group III patients were attributable to single or multiple recurrences, subsequent operations or radiation therapy, and severe hypotha- lamic morbidity (such as morbid obesity, adipsic diabetes insipidus, and related fluid and electrolyte imbalance).

There was no significant difference in the OS and PFS rates between patients with childhood- and adult-onset disease $(p=0.421$ and $p=0.956$, respectively; Fig. 11). Furthermore, there was no significant difference in the OS and PFS rates among patients with different pathological subtypes ( $p=0.14$ and $p=0.556$, respectively; Fig. 12$)$. However, there was a significant difference in the OS and PFS rates among different growth pattern groups. Patients in Group III (Sp-CPs) showed substantially lower OS and PFS rates as compared with patients in the other 2 groups ( $\mathrm{p}=0.053$ and $\mathrm{p}=0.001$, respectively; Fig. 13).

\section{Discussion}

\section{Growth Patterns of CPs}

Classifying CPs based on their anatomical location or relationship to neural structures (optic chiasm or TVF) may not accurately clarify the growth pattern. Each basic growth pattern has a definite topographic relationship to sellar membranous structures and represents tumor growth at its initial stage. In this study, CPs were classified into 3 groups based on growth pattern, including infradiaphragmatic, suprasellar subarachnoid extraventricular, and suprasellar subpial ventricular growth. The complex growth of tumors at their final stage could be interpreted using these basic growth patterns alone or in combination.

\section{Classification and Tumor-Meningeal Relationships in CPs}

Previous CP classification systems can be generally divided into 2 categories. Classification systems in the first category include those based on tumor topographic relationships to the sellar diaphragm, ${ }^{6,63}$ optic chiasm, ${ }^{27}$ pituitary stalk,,$^{32}$ and TVF. ${ }^{58}$ Classification systems in the second category include those based on tumor location and vertical extension (e.g., Samii and colleagues ${ }^{54,55}$ ). These systems classify CPs as follows: Grade I, intrasellar or infradiaphragmatic; Grade II, occupying the cistern with or without an intrasellar component; Grade III, occupying the lower half of the third ventricle; Grade IV, occupying 

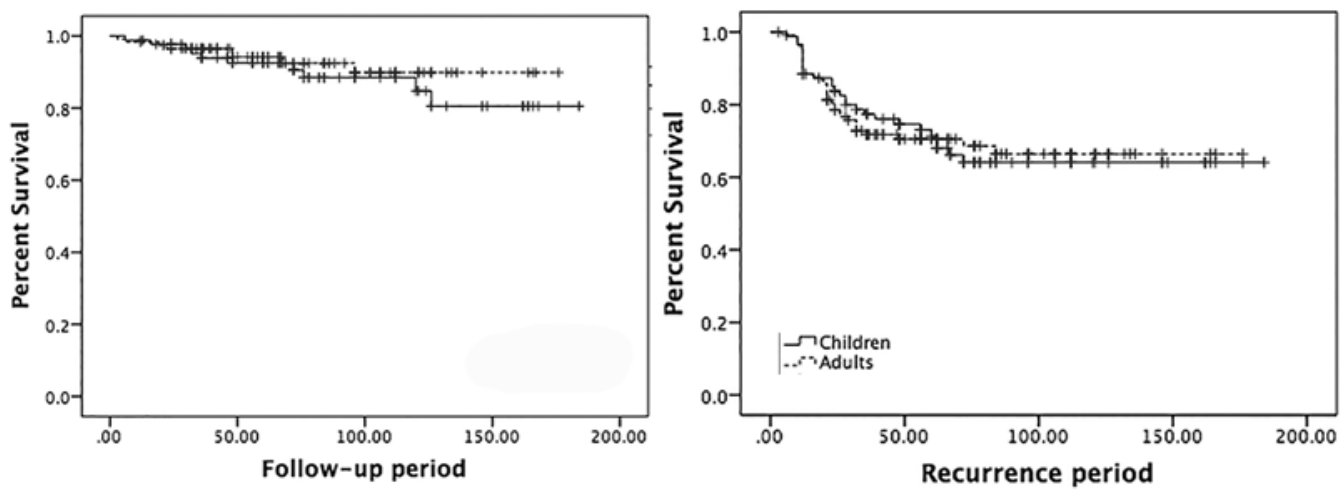

FIG. 11. Survival curves for patients with childhood- and adult-onset tumors. The survival diagrams show that there was no significant difference in the OS (left) and PFS (right) rates between patients with childhood-and adult-onset disease $(p=0.421$ and $p=$ 0.956 , respectively, log-rank test).

the upper half of the third ventricle; and Grade V, reaching the septum pellucidum or lateral ventricles. These systems are useful in understanding tumor growth and provide clues that aid in the selection of the optimal surgical approach for tumor removal. However, even with the use of these classification systems, it is not uncommon to find that the relationship and adherence between the tumor and surrounding neurovascular structures are quite different, even in cases with a similar neuroradiological appearance. This is explained as follows: 1) all of these classification systems are based on neuroradiological appearance, which represents the final tumor stage at the time of diagnosis; 2) although some tumors may exhibit similar growth on radiological evaluation at the time of diagnosis, their exact origin and relationship to surrounding structures may differ at onset; and 3) large tumors may severely compress, distort, or involve neural tissue (TVF, pituitary stalk, and optic tract structures), making preoperative evaluation difficult even with excellent-quality neuroradiological studies. ${ }^{1,2,25,28}$ Therefore, it is crucial to understand CP growth and to appreciate its effect on the distortion and displacement of vital neurovascular structures intraoperatively.

Erdheim ${ }^{21}$ was the first to theorize that CPs arise embryologically from an incompletely involuted craniopharyngeal duct. According to his pioneering histological findings, the nests of epithelial cell remnants that give rise to CPs are mainly found in 2 areas: the anterior-superior surface of the junction of the pituitary gland and stalk and the interface between the pars tuberalis and infundibulum. It is reasonable to speculate that $\mathrm{CP}$ development from these nests would give rise to subdiaphragmatic CPs and suprasellar CPs, respectively. Our review of MR images and intraoperative findings for the 226 patients with CP in our study was compatible with this hypothesis. We found that all the tumors could be classified as having either an infradiaphragmatic (infrasellar/infradiaphragmatic CPs) or an infundibulotuberal (suprasellar infundibular CPs) origin. Suprasellar infundibular CPs will push along the path of least resistance, which is dependent on tumor origin (superficial near the pia matter [corresponding to a lower site of origin] or deep to the ependymal layer) and, in certain cases, tumor position relative to the optic chiasm. This results in 2 kinds of tumors: 1) those with preferential subarachnoid growth, and 2) those with preferential ventricular growth. Therefore, we classified CPs into 3 groups: Group I (Id-CPs), tumors with an infradiaphragmatic origin and an extraarachnoid tumor-meningeal relationship at onset; Group II (Sa-CPs), tumors with suprasellar extraventricular development and a subarachnoid extrapial tumor-meningeal relationship; and Group III (Sp-CPs), tumors with suprasellar ventricular development and a subarachnoid subpial tumor-meningeal relationship.
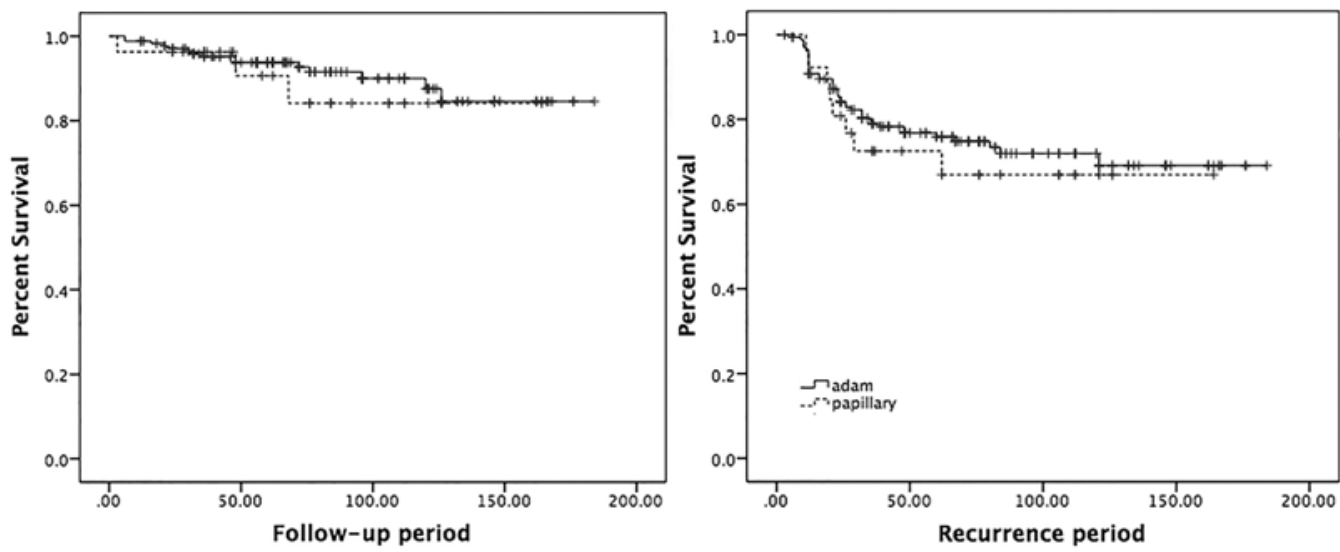

FIG. 12. Survival curves for patients with different tumor pathological subtypes. There was no significant difference in the OS (left) and PFS (right) rates between patients with ACP and squamous PCP $(p=0.14$ and $p=0.556$, respectively, log-rank test). 

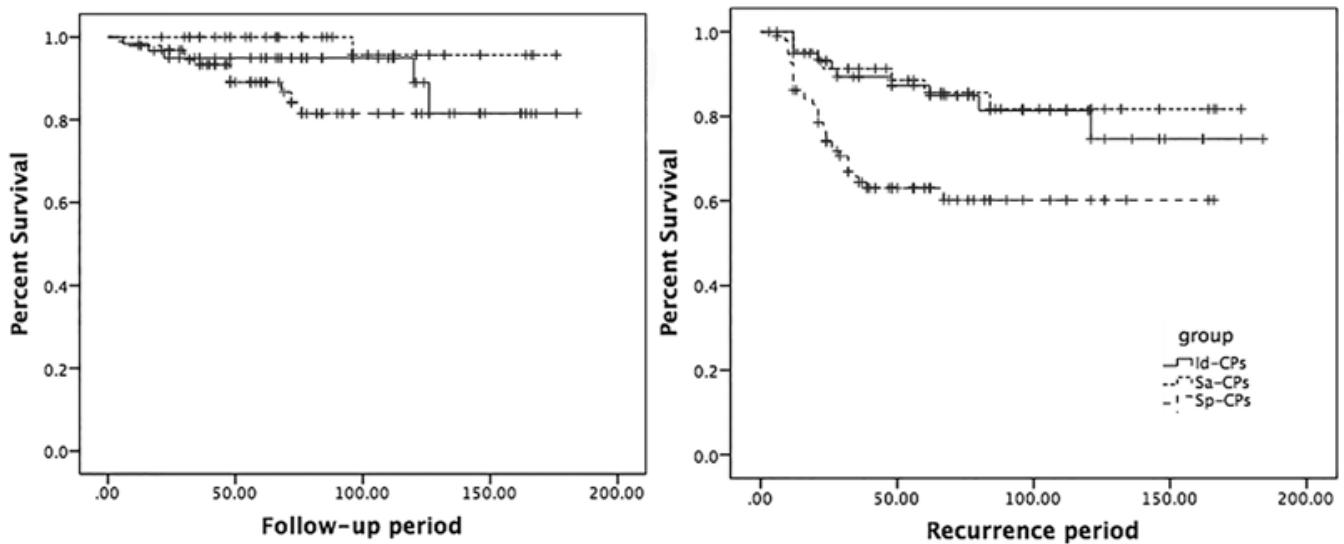

FIG. 13. Survival curves for patients with different tumor growth. Left: OS diagram shows that the survival percentage for Sp-CPs is lower than that for Id-CPs and Sa-CPs. This difference reached statistical significance $(p=0.053$, log-rank test). Right: There was a significant difference in the recurrence-free survival rates between groups. Patients with Sp-CPs showed substantially lower PFS rates as compared with patients from the other 2 groups (at 5 years: $63 \%$ vs $85 \%$ and $86 \%$; at 10 years: $60 \%$ vs $81 \%$ and $82 \% ; p=0.001$, log-rank test).

\section{Differences in Growth Patterns Between Juvenile and Adult Cases}

Variability in $\mathrm{CP}$ growth patterns between adults and children has not been noted in previously published data. However, a literature review may provide some clues regarding this issue. Studies focusing on pediatric CPs have provided detailed data on tumor growth patterns. These studies have shown that infradiaphragmatic tumors always constitute an important subtype of CPs. Using Choux-Raybaud's ${ }^{6}$ classification, Lee et al..$^{38}$ reported that 27 (40.9\%) and $39(59.1 \%)$ of 66 pediatric CPs were purely intrasellar and TVF CPs, respectively. Wang et al. ${ }^{63}$ analyzed the radiological, operative, and pathological findings of 25 consecutive pediatric $\mathrm{CP}$ patients. They found that the tumors in $14(56 \%)$ patients had characteristics of the infradiaphragmatic subtype, including prechiasmatic growth and a layer of sellar diaphragm covering the tumor top, whereas the tumors in the other 11 patients had retrochiasmatic growth and a centered TVF. Lena et al. ${ }^{39}$ provided detailed topographic CP data from a cohort of 47 children. They classified tumors into 4 types: purely intrasellar (14/47 [29.8\%]), tuberoinfundibular (25/47 [53.2\%]), strictly intraventricular (1/47 [2\%]), and global or giant (7/47 [14.9\%]). In our last series, $42 \%$ (34/81) of pediatric CPs were infradiaphragmatic tumors. ${ }^{50}$ Interestingly, none of these studies included an extraventricular subtype in the tumor classification. Few studies have specifically addressed Id-CPs in adult patients, which is most likely because of their rarity in the adult population. Based on the literature, purely intrasellar CPs represent the least common variety in both children and adults. ${ }^{22,31,61,64}$ Besides differences in Id-CP incidence between children and adults, our results revealed that tumor size and anatomical location also differed according to age. Juvenile Id-CP usually represents a crucial variant and has a wide spectrum of tumor origins (from the nasopharynx to the pituitary chamber), whereas adult Id-CP is usually confined within the sellar, intrasellar, or suprasellar regions and has a more benign nature. However, several studies have shown the predominance of intraventricular lesions in older patients. ${ }^{4,29,44,45}$ These findings have been replicated in this study and are in ac- cordance with the purely suprasellar subpial ventricular growth pattern in our classification scheme.

Another important issue to consider when analyzing the difference between juvenile and adult CPs are the 2 histological variants: ACP, the typical pediatric form, and PCP, observed almost exclusively in adults. Recently, it was reported that $95 \%$ of PCPs contain $B R A F$ p.V600E mutations, ${ }^{5}$ and $C T N N B 1$ and $B R A F$ mutations are mutually exclusive and specific to tumor pathological subtype. Larkin et al. ${ }^{34}$ examined the relationship between mutations in CTNNBI and BRAF and the subcellular location of $\beta$-catenin in a series of 37 patients with CPs. They found BRAF V600E mutations in $81 \%$ (17 of 21) of PCPs by targeted Sanger sequencing and in $86 \%$ (18 of 21) of PCPs by immunohistochemistry. In all ACPs, translocation of $\beta$-catenin from the membrane to the cytosol/ nucleus was observed. Of 16 patients with ACP, 14 (88\%) were found to have $B R A F$ wild-type tumors by sequencing and immunohistochemistry. These studies suggest that the genetics of these tumors may be different. We compared the growth patterns of ACPs between children and adults. The result showed that the difference persisted, indicating that the difference in tumor growth patterns between children and adults cannot be simply attributed to pathological type. Whether this difference is associated with different mechanisms of tumorigenesis between children and adults deserves further study.

Of note, we found that morphological distortion of hypothalamic structures differs between children and adults with Sp-CPs. Few studies have specifically addressed the degree of hypothalamic involvement in children versus adults. However, we can draw some conclusions by analyzing patient outcomes through a literature review. In a study of 63 childhood CP survivors, all patients with marked obesity after surgery had evidence of significant alterations in the normal hypothalamic anatomy, with MR images showing either complete deficiency or extensive destruction of the TVF. ${ }^{15}$ It is widely accepted that obesity is the most frequent manifestation of hypothalamic damage following CP surgery. De Vile et al. ${ }^{16}$ found that a young age at presentation was a significant predictor of hypotha- 
lamic morbidity. These findings are compatible with our morphological analysis of Group III tumors. Juvenile tumors had a higher probability of exhibiting a combination of transstalk and subarachnoid subpial ventricular growth patterns, whereas adult tumors tended to exhibit a pure subarachnoid subpial ventricular growth pattern. Morphological distortion of hypothalamic structures is not necessarily associated with significant hypothalamic morbidity. We believe that childhood Sp-CPs more severely violate hypothalamic structures as compared with adult Sp-CPs. However, it is difficult to determine whether this reflects the vulnerability of hypothalamic structures in children or differences in tumor genetics between children and adults.

Previous studies on the impact of age on prognosis and survival in patients with CP have provided inconsistent results. Better outcome in younger patients, $, 22,59$ better outcome in older patients, ${ }^{8,51}$ and similar outcome between younger and older patients ${ }^{31,42,47,48}$ have all been reported. These contradictory data warrant cautious interpretation, as a detailed topographic comparison of CPs between adults and children was not provided in most of these studies. Differences in tumor growth patterns may influence therapeutic options and therefore clinical outcomes. Thus, discrepancies in the prognostic significance of age in $\mathrm{CP}$ patients may be due in part to the variability in tumor growth patterns between children and adults. Therefore, we believe that a hierarchical comparison is necessary when investigating outcomes and survival across age groups in patients with CP.

\section{Clinical Relevance of Tumor Growth Patterns}

Our topographic classification scheme highlights the original tumor site and the relationship between the tumor and suprasellar membranous structures. In $\mathrm{CP}$, the point of origin determines the preferential regional expansion of the tumor and therefore influences morbidity in terms of both pituitary and hypothalamic damage. Our topographic classification scheme provides more details of tumor-hypothalamus relationships. Each tumor group has a distinct involvement pattern toward the hypothalamic-pituitary axis. Id-CPs mainly involve the pituitary gland and the distal portion of the stalk, while Sp-CPs mainly involve the third ventricle and hypothalamic structures. The analysis of our clinical data confirmed that Id-CPs are more likely to be associated with pituitary dysfunction and visual symptoms, and that Sp-CPs are more likely to be associated with symptoms related to increased intracranial pressure and mental problems related to hypothalamic dysfunction. Furthermore, our classification system might serve as 1 of the criterion for surgical planning. It is well known that a transsphenoidal or transcranial extraaxial approach is most appropriate to treat the majority of patients with Id-CP. The diaphragm and overlay arachnoid can serve as the dissecting plane during operation. An understanding of this topographic relationship is mandatory to perform radical resection and minimize damage to hypothalamic structures. However, for large tumors with combination growth patterns, an intraaxial route may be required to dissect the tumor from the parenchyma around the third ventricle walls. For these massive lesions, some authors advocate a 2-stage removal that involves transsphenoidal debulking, followed by craniotomy. They believe this approach may allow the tumor to descend caudally, facilitating its further resection during the second surgery. ${ }^{18,41}$ The extraventricular location of Sa-CPs adjudicates the extraaxial route, as the arachnoid membrane surrounding the tumor provides a plane of cleavage for tumor dissection. ${ }^{1,222,26,58,64}$ This approach offers a high probability of preserving the integrity of the pituitary stalk and hypothalamus-hypophysis axis. The surgical removal of $\mathrm{Sp}-\mathrm{CPs}$ always necessitates an intraaxial route (the translamina terminalis route as a primary or supplemental corridor) for the dissection of the tumor from the nervous tissue parenchyma of the third ventricle walls. Therefore, radical removal of these tumors usually necessitates craniotomy to dissect the tumor under direct vision. Nevertheless, tumor extension through the TVF toward the subarachnoid space would create an artificial corridor to reach the tumor via an extraaxial route. ${ }^{22}$ Recently, endoscopy has been used in the transsphenoidal supradiaphragmatic approach. Several studies have demonstrated successful tumor removal using an extended endoscopic endonasal approach. However, longer followup studies are needed to confirm its long-term effectiveness. ${ }^{10-14,19,23,24,30,32,35-37,40,41,57,60}$

\section{Implications for CP Treatment Strategy}

The optimal therapeutic approach for $\mathrm{CP}$ remains controversial. Some authors suggest complete removal as the primary treatment goal to avoid radiation exposure to the developing brain, ,222,27,61,64 whereas others advocate less aggressive surgery combined with radiotherapy as an effective means of preventing recurrence. $916,17,20,43,51,52,65$ Development of an intermediate approach using clear objective criteria and identification of guidelines to determine the best surgical approach (radical vs conservative) are ongoing challenges for neurosurgeons. For the majority of patients with Id-CPs and Sa-CPs, radical tumor removal is associated with long-term tumor control and a low likelihood of postoperative hypothalamic dysfunction. On the contrary, the growth of Sp-CPs results in the gross morphological distortion of the hypothalamus, which makes surgical manipulation of this area potentially hazardous. In our series, $39 \%$ of patients with Sp-CPs experienced significant weight gain after radical tumor removal, indicating that gross-total removal of these tumors requires caution. In addition, nearly one-third of patients with SpCPs did not achieve total removal even after aggressive surgery; the higher rate of recurrence may also be related to the significantly decreased likelihood of total resection in this group. All these data indicate that tumor growth patterns and resectability are important factors when defining a treatment plan for patients with $\mathrm{CP}$.

Further studies are necessary to more accurately address CP topography and individual surgical risk associated with radical lesion removal for Sp-CPs. Currently, we believe that a large deficient TVF with sacrifice of the infundibulum and stalk should be avoided when performing gross-total removal during CP surgery, of which children with $\mathrm{Sp}$-CPs are at increased risk given that childhood tumors more severely violate hypothalamic structures.

In addition to its importance in selecting a surgical strategy for tumor removal, tumor classification should also be 
considered in selecting postoperative supplementary radiotherapy. For instance, recurrent tumors located in crucial areas, such as the parenchymal layer of the TVF (Sp-CPs), make a second surgery more difficult. Therefore, the indication for radiotherapy for these types of tumors should be broadened. Nonetheless, Id-CPs and Sa-CPs (Groups I and II) may not necessitate radiotherapy and have a high probability of safe reoperation in cases of recurrence.

\section{Conclusions}

$\mathrm{CP}$ is an extremely formidable tumor that poses a significant surgical challenge. We propose a clinical classification system based on the site of tumor origin and the relationship of the tumor to the arachnoid membrane and surrounding structures. This classification system improves our understanding of the morphological features and growth patterns of CPs. More tailored, individualized surgical strategies based on tumor growth patterns are mandatory to provide long-term tumor control and to minimize damage to hypothalamic structures. Differences in $\mathrm{CP}$ growth patterns between children and adults indicate the need for hierarchical comparison in future CP studies.

\section{References}

1. Al-Mefty O, Ayoubi S, Kadri PA: The petrosal approach for the total removal of giant retrochiasmatic craniopharyngiomas in children. J Neurosurg 106 (2 Suppl):87-92, 2007

2. Al-Mefty O, Hassounah M, Weaver P, Sakati N, Jinkins JR, Fox JL: Microsurgery for giant craniopharyngiomas in children. Neurosurgery 17:585-595, 1985

3. Baskin DS, Wilson CB: Surgical management of craniopharyngiomas. A review of 74 cases. J Neurosurg 65:22-27, 1986

4. Behari S, Banerji D, Mishra A, Sharma S, Sharma S, Chhabra DK, et al: Intrinsic third ventricular craniopharyngiomas: report on six cases and a review of the literature. Surg Neurol 60:245-253, 2003

5. Brastianos PK, Taylor-Weiner A, Manley PE, Jones RT, DiasSantagata D, Thorner AR, et al: Exome sequencing identifies BRAF mutations in papillary craniopharyngiomas. Nat Genet 46:161-165, 2014

6. Brunel H, Raybaud C, Peretti-Viton P, Lena G, Girard N, PazParedes A, et al: [Craniopharyngioma in children: MRI study of 43 cases.] Neurochirurgie 48:309-318, 2002 (Fr)

7. Bülow B, Attewell R, Hagmar L, Malmström P, Nordström $\mathrm{CH}$, Erfurth EM: Postoperative prognosis in craniopharyngioma with respect to cardiovascular mortality, survival, and tumor recurrence. J Clin Endocrinol Metab 83:3897-3904, 1998

8. Bunin GR, Surawicz TS, Witman PA, Preston-Martin S, Davis F, Bruner JM: The descriptive epidemiology of craniopharyngioma. J Neurosurg 89:547-551, 1998

9. Caldarelli M, Massimi L, Tamburrini G, Cappa M, Di Rocco C: Long-term results of the surgical treatment of craniopharyngioma: the experience at the Policlinico Gemelli, Catholic University, Rome. Childs Nerv Syst 21:747-757, 2005

10. Campbell PG, McGettigan B, Luginbuhl A, Yadla S, Rosen M, Evans JJ: Endocrinological and ophthalmological consequences of an initial endonasal endoscopic approach for resection of craniopharyngiomas. Neurosurg Focus 28(4):E8, 2010

11. Cappabianca P, Cavallo LM: The evolving role of the transsphenoidal route in the management of craniopharyngiomas. World Neurosurg 77:273-274, 2012

12. Cavallo LM, Prevedello DM, Solari D, Gardner PA, Esposito F, Snyderman $\mathrm{CH}$, et al: Extended endoscopic endonasal transsphenoidal approach for residual or recurrent craniopharyngiomas. J Neurosurg 111:578-589, 2009

13. Cavallo LM, Solari D, Esposito F, Cappabianca P: The endoscopic endonasal approach for the management of craniopharyngiomas involving the third ventricle. Neurosurg Rev 36:27-38, 2013

14. de Divitiis E, Cappabianca P, Cavallo LM, Esposito F, de Divitiis O, Messina A: Extended endoscopic transsphenoidal approach for extrasellar craniopharyngiomas. Neurosurgery 61 (5 Suppl 2):219-228, 2007

15. de Vile CJ, Grant DB, Hayward RD, Kendall BE, Neville BG, Stanhope R: Obesity in childhood craniopharyngioma: relation to post-operative hypothalamic damage shown by magnetic resonance imaging. J Clin Endocrinol Metab 81:2734-2737, 1996

16. De Vile CJ, Grant DB, Kendall BE, Neville BG, Stanhope R, Watkins KE, et al: Management of childhood craniopharyngioma: can the morbidity of radical surgery be predicted? $\mathbf{J}$ Neurosurg 85:73-81, 1996

17. Dhellemmes P, Vinchon M: Radical resection for craniopharyngiomas in children: surgical technique and clinical results. J Pediatr Endocrinol Metab 19 (Suppl 1):329-335, 2006

18. Duff J, Meyer FB, Ilstrup DM, Laws ER Jr, Schleck CD, Scheithauer BW: Long-term outcomes for surgically resected craniopharyngiomas. Neurosurgery 46:291-305, 2000

19. Dusick JR, Esposito F, Kelly DF, Cohan P, DeSalles A, Becker DP, et al: The extended direct endonasal transsphenoidal approach for nonadenomatous suprasellar tumors. J Neurosurg 102:832-841, 2005

20. Elliott RE, Hsieh K, Hochm T, Belitskaya-Levy I, Wisoff J, Wisoff JH: Efficacy and safety of radical resection of primary and recurrent craniopharyngiomas in 86 children. J Neurosurg Pediatr 5:30-48, 2010

21. Erdheim J: Über Hypophysengangsgeschwulste und Hirmcholesteatome. Sitzungsb Kais Akad Wissen Math Naturw Klin 113:537-726, 1904

22. Fahlbusch R, Honegger J, Paulus W, Huk W, Buchfelder M: Surgical treatment of craniopharyngiomas: experience with 168 patients. J Neurosurg 90:237-250, 1999

23. Frank G, Pasquini E, Doglietto F, Mazzatenta D, Sciarretta V, Farneti G, et al: The endoscopic extended transsphenoidal approach for craniopharyngiomas. Neurosurgery 59 (1 Suppl 1):ONS75-83, 2006

24. Gardner PA, Kassam AB, Snyderman CH, Carrau RL, Mintz $\mathrm{AH}$, Grahovac S, et al: Outcomes following endoscopic, expanded endonasal resection of suprasellar craniopharyngiomas: a case series. J Neurosurg 109:6-16, 2008

25. Hald JK, Eldevik OP, Quint DJ, Chandler WF, Kollevold T: Pre- and postoperative MR imaging of craniopharyngiomas. Acta Radiol 37:806-812, 1996

26. Hoffman HJ: Surgical management of craniopharyngioma. Pediatr Neurosurg 21 (Suppl 1):44-49, 1994

27. Hoffman HJ, De Silva M, Humphreys RP, Drake JM, Smith ML, Blaser SI: Aggressive surgical management of craniopharyngiomas in children. J Neurosurg 76:47-52, 1992

28. Hoffman HJ, Hendrick EB, Humphreys RP, Buncic JR, Armstrong DL, Jenkin RD: Management of craniopharyngioma in children. J Neurosurg 47:218-227, 1977

29. Ikezaki K, Fujii K, Kishikawa T: Magnetic resonance imaging of an intraventricular craniopharyngioma. Neuroradiology 32:247-249, 1990

30. Jane JA Jr, Kiehna E, Payne SC, Early SV, Laws ER Jr: Early outcomes of endoscopic transsphenoidal surgery for adult craniopharyngiomas. Neurosurg Focus 28(4):E9, 2010

31. Karavitaki N, Brufani C, Warner JT, Adams CB, Richards P, Ansorge $\mathrm{O}$, et al: Craniopharyngiomas in children and adults: systematic analysis of 121 cases with long-term follow-up. Clin Endocrinol (Oxf) 62:397-409, 2005

32. Kassam AB, Gardner PA, Snyderman CH, Carrau RL, Mintz 
AH, Prevedello DM: Expanded endonasal approach, a fully endoscopic transnasal approach for the resection of midline suprasellar craniopharyngiomas: a new classification based on the infundibulum. J Neurosurg 108:715-728, 2008

33. Kitano M, Taneda M: Extended transsphenoidal surgery for suprasellar craniopharyngiomas: infrachiasmatic radical resection combined with or without a suprachiasmatic translamina terminalis approach. Surg Neurol 71:290-298, 2009

34. Larkin SJ, Preda V, Karavitaki N, Grossman A, Ansorge O: BRAF V600E mutations are characteristic for papillary craniopharyngioma and may coexist with CTNNB1-mutated adamantinomatous craniopharyngioma. Acta Neuropathol 127:927-929, 2014

35. Laufer I, Anand VK, Schwartz TH: Endoscopic, endonasal extended transsphenoidal, transplanum transtuberculum approach for resection of suprasellar lesions. J Neurosurg 106:400-406, 2007

36. Laws ER Jr: Surgical outcome in 90 patients with craniopharyngiomas: an evaluation of the transsphenoidal approach. World Neurosurg 74:254-255, 2010

37. Laws ER, Kanter AS, Jane JA Jr, Dumont AS: Extended transsphenoidal approach. J Neurosurg 102:825-828, 2005

38. Lee YY, Wong TT, Fang YT, Chang KP, Chen YW, Niu DM: Comparison of hypothalamopituitary axis dysfunction of intrasellar and third ventricular craniopharyngiomas in children. Brain Dev 30:189-194, 2008

39. Lena G, Paz Paredes A, Scavarda D, Giusiano B: Craniopharyngioma in children: Marseille experience. Childs Nerv Syst 21:778-784, 2005

40. Maira G, Anile C, Albanese A, Cabezas D, Pardi F, Vignati A: The role of transsphenoidal surgery in the treatment of craniopharyngiomas. J Neurosurg 100:445-451, 2004

41. Maira G, Anile C, Rossi GF, Colosimo C: Surgical treatment of craniopharyngiomas: an evaluation of the transsphenoidal and pterional approaches. Neurosurgery 36:715-724, 1995

42. Manaka S, Teramoto A, Takakura K: The efficacy of radiotherapy for craniopharyngioma. J Neurosurg 62:648-656, 1985

43. Merchant TE, Kiehna EN, Kun LE, Mulhern RK, Li C, Xiong X, et al: Phase II trial of conformal radiation therapy for pediatric patients with craniopharyngioma and correlation of surgical factors and radiation dosimetry with change in cognitive function. J Neurosurg 104 (2 Suppl):94-102, 2006

44. Pascual JM, Carrasco R, Prieto R, Gonzalez-Llanos F, Alvarez F, Roda JM: Craniopharyngioma classification. J Neurosurg 109:1180-1183, 2008

45. Pascual JM, González-Llanos F, Barrios L, Roda JM: Intraventricular craniopharyngiomas: topographical classification and surgical approach selection based on an extensive overview. Acta Neurochir (Wien) 146:785-802, 2004

46. Pascual JM, Prieto R, Castro-Dufourny I, Gil-Simoes R, Carrasco R: Classification systems of adult craniopharyngiomas: the need for an accurate definition of the hypothalamustumor relationships. Arch Med Res 43:588-590, author reply 591, 2012

47. Pemberton LS, Dougal M, Magee B, Gattamaneni HR: Experience of external beam radiotherapy given adjuvantly or at relapse following surgery for craniopharyngioma. Radiother Oncol 77:99-104, 2005

48. Petito CK, DeGirolami U, Earle KM: Craniopharyngiomas: a clinical and pathological review. Cancer 37:1944-1952, 1976

49. Qi S, Lu Y, Pan J, Zhang X, Long H, Fan J: Anatomic relations of the arachnoidea around the pituitary stalk: relevance for surgical removal of craniopharyngiomas. Acta Neurochir (Wien) 153:785-796, 2011

50. Qi S, Pan J, Lu Y, Gao F, Cao Y, Peng J, et al: The impact of the site of origin and rate of tumour growth on clinical outcome in children with craniopharyngiomas. Clin Endocrinol (Oxf) 76:103-110, 2012
51. Rajan B, Ashley S, Gorman C, Jose CC, Horwich A, Bloom $\mathrm{HJ}$, et al: Craniopharyngioma--a long-term results following limited surgery and radiotherapy. Radiother Oncol 26:1-10, 1993

52. Regine WF, Kramer S: Pediatric craniopharyngiomas: long term results of combined treatment with surgery and radiation. Int J Radiat Oncol Biol Phys 24:611-617, 1992

53. Sainte-Rose C, Puget S, Wray A, Zerah M, Grill J, Brauner $\mathrm{R}$, et al: Craniopharyngioma: the pendulum of surgical management. Childs Nerv Syst 21:691-695, 2005

54. Samii M, Bini W: Surgical treatment of craniopharyngiomas. Zentralbl Neurochir 52:17-23, 1991

55. Samii M, Tatagiba M: Surgical management of craniopharyngiomas: a review. Neurol Med Chir (Tokyo) 37:141-149, 1997

56. Song-tao Q, Xi-an Z, Hao L, Jun F, Jun P, Yun-tao L: The arachnoid sleeve enveloping the pituitary stalk: anatomical and histologic study. Neurosurgery 66:585-589, 2010

57. Stamm AC, Vellutini E, Harvey RJ, Nogeira JF Jr, Herman DR: Endoscopic transnasal craniotomy and the resection of craniopharyngioma. Laryngoscope 118:1142-1148, 2008

58. Steno J, Malácek M, Bízik I: Tumor-third ventricular relationships in supradiaphragmatic craniopharyngiomas: correlation of morphological, magnetic resonance imaging, and operative findings. Neurosurgery 54:1051-1060, 2004

59. Sun HI, Akgun E, Bicer A, Ozkan A, Bozkurt SU, Kurtkaya $\mathrm{O}$, et al: Expression of angiogenic factors in craniopharyngiomas: implications for tumor recurrence. Neurosurgery 66:744-750, 2010

60. Thompson D, Phipps K, Hayward R: Craniopharyngioma in childhood: our evidence-based approach to management. Childs Nerv Syst 21:660-668, 2005

61. Van Effenterre R, Boch AL: Craniopharyngioma in adults and children: a study of 122 surgical cases. J Neurosurg 97:3-11, 2002

62. Wang KC, Hong SH, Kim SK, Cho BK: Origin of craniopharyngiomas: implication on the growth pattern. Childs Nerv Syst 21:628-634, 2005

63. Wang KC, Kim SK, Choe G, Chi JG, Cho BK: Growth patterns of craniopharyngioma in children: role of the diaphragm sellae and its surgical implication. Surg Neurol 57:25-33, 2002

64. Yaşargil MG, Curcic M, Kis M, Siegenthaler G, Teddy PJ, Roth P: Total removal of craniopharyngiomas. Approaches and long-term results in 144 patients. J Neurosurg 73:3-11, 1990

65. Zuccaro G: Radical resection of craniopharyngioma. Childs Nerv Syst 21:679-690, 2005

\section{Disclosures}

The authors report no conflict of interest concerning the materials or methods used in this study or the findings specified in this paper.

\section{Author Contributions}

Conception and design: Qi, Pan. Acquisition of data: Pan, Liu, Lu, Peng, Zhang, Xu, Huang, Fan. Analysis and interpretation of data: Qi, Pan, Lu, Xu, Huang. Drafting the article: Pan. Critically revising the article: Qi, Pan. Reviewed submitted version of manuscript: Pan. Statistical analysis: Liu, Peng, Zhang, Fan. Administrative/technical/material support: Liu, Fan. Study supervision: Qi.

\section{Correspondence}

SongTao Qi, Department of Neurosurgery, Nanfang Hospital, \#1838 North Guangzhou Ave., Guangzhou 510515, China. email: sjwk_songtao@hotmail.com. 